\title{
Outstanding Chiroptical Features of Thin Films of Chiral Oligothiophenes
}

\author{
Gianluigi Albano, ${ }^{[\mathrm{a}]}$ Francesco Salerno, ${ }^{[\mathrm{a}]}$ Lorenzo Portus, ${ }^{[\mathrm{a}]}$ William Porzio,${ }^{[\mathrm{b}]}$ Laura Antonella Aronica, ${ }^{[\mathrm{a}]}$ \\ and Lorenzo Di Bari ${ }^{\star[a]}$
}

\begin{abstract}
Recently we described a chiral benzo[1,2-b:4,5 $b$ ]dithiophene-based oligothiophene with the very uncommon chiroptical property of (signal inversion on sample flipping. This is due to the interference between linear dichroism and linear birefringence, called LDLB effect, which is theoretically well understood, but to date very rarely reported in the literature. Samples with very large LDLB effect lead to the unique possibility of discriminating the direction of sample illumination, if from front or back. We present a set of analogue compounds, where we introduce small structural changes aiming to reveal which factors determine very large LDLB effect or true circular dichroism allied to supramolecular chirality. We reveal the primary impact of the deposition technique, where spin coating may exert a primary role, and let us obtain films with outstanding chiroptical features. These features are made even more relevant on account of semiconducting properties of oligothiophenes in view of optical sensing applications.
\end{abstract}

\section{Introduction}

Chirality in organic optoelectronic devices is a topic, which is rapidly gaining interest. ${ }^{[1-3]}$ There is at least a two-fold interest: in the first place it can constitute a means to drive and control the supramolecular order of $\pi$-conjugated molecules constituting the active layers of the devices, ${ }^{[4-5]}$ and secondly it opens the way to highly specialized applications, such as producing (CP-OLED) ${ }^{[6-}$ ${ }^{8]}$ or detecting (CP-OFET) ${ }^{\text {[9-12] }}$ circularly polarized (CP) light or specifically responding to analyte enantiomers in analytical sensors. ${ }^{[13-14]}$ Moreover, molecular chirality is a unique way to manipulate electron spins and to construct spin filters. ${ }^{[15]}$ Finally, chiral nanostructures of $\pi$-conjugated polymers and oligomers are often desirable because they prevent parallel stack of molecules, which would lead to short exciton lifetime. ${ }^{[16]}$

[a] G. Albano, F. Salerno, L. Portus, Dr. L. A. Aronica, Prof. L. Di Bari Dipartimento di Chimica e Chimica Industriale Università di Pisa

Via Giuseppe Moruzzi 13, 56124 Pisa, Italy

E-mail: lorenzo.dibari@unipi.it

[b] W. Porzio

Istituto per lo Studio delle Macromolecole (ISMAC)

Consiglio Nazionale delle Ricerche

Via Edoardo Bassini 15, 20133 Milano, Italy

F. Salerno's Present Address:

Centre for Plastic Electronics

Imperial College London, South Kensington Campus

London SW7 2AZ, UK

Supporting information for this article can be found under: https://doi.org/10.1002/cnma.2018xxxxx
In this perspective, electronic circular dichroism (ECD) goes well beyond the traditional use for studying molecular and supramolecular chirality, allied to its unique sensitivity to the reciprocal arrangement of chromophores at the nanoscale. ${ }^{[17]}$ On the contrary, it will become a new paradigm to characterize intrinsic properties of chiral materials based on $\pi$-conjugated molecules, to be used as the active element of optical detectors. A current research goal is to obtain thin films of organic semiconductors displaying high or very high discrimination of CP-light both in absorption (ECD) or in emission (circularly polarized luminescence, $\mathrm{CPL}$ ), which is conveniently measured by the so-called anisotropy $g$-factor. In the case of absorption, it can be shortly defined as

$$
g=\mathrm{ECD} / \mathrm{Abs}
$$

It is worth recalling that the $g$-factor is a pure number, independent of the pathlength and of the sample concentration and for this reason ideal to characterize thin films.

Recently, squaraine compounds incorporating $L$-proline as the chiral element where shown to provide thin films with large $g$ factor (above $2 \cdot 10^{-2}$ at $770 \mathrm{~nm}$ ). ${ }^{[12]}$

When applying chiroptical methods to thin films, one needs to recall a basic concept of Mueller matrix analysis: ${ }^{[18-20]}$ because of possible anisotropies, the recorded ECD signal for solid state samples is the sum of different terms, whose foremost contributions are

$\mathrm{CD}_{\text {obs }} \approx \mathrm{CD}_{\text {iso }}+1 / 2\left(\mathrm{LD}^{\prime} \cdot \mathrm{LB}+\mathrm{LD} \cdot \mathrm{LB}^{\prime}\right)+(\mathrm{LD} \cdot \sin \alpha+\mathrm{LB}) \cdot \cos 2 \theta$

where $C D_{\text {iso }}$, $L D$ and $L B$ represent the intrinsic isotropic component of circular dichroism (i.e. the part which is independent of sample orientation), linear dichroism and linear birefringence, respectively; the prime in the products LD'.LB and LD. LB' indicates $a+45^{\circ}$ shift between LD and LB axes, while $\theta$ describes sample rotation around the optical axis and $\alpha$ is related to the residual birefringence of the photoelastic modulator (PEM), used to generate circularly polarized (CP) radiation. ${ }^{[21]}$

The third term of Eq. (2) is surely an artifact, which arises from the limited technical possibility to realize a "perfect" ECD experiment. To overcome this problem, Kuroda et al. designed and built a Universal Chiroptical Spectrophotometer (UCS-1: J$800 \mathrm{KCM}$ ) for obtaining artifact-free ECD spectra of solid-state samples. ${ }^{[22]}$ In a conventional instrument, any change in the spectra by rotating the sample around the optical axis - which corresponds to changing $\theta$ in Eq. (2) - reveals the presence of this artifact and ultimately the global LD of the sample, while the LB contribution can be expected to be less apparent. In all the cases discussed below, we invariably observed perfectly conserved spectra upon sample rotation, which excludes any 
contribution from this term, which will be safely neglected in the following.

The second term of Eq. (2), $1 / 2\left(\mathrm{LD}^{\prime} \cdot \mathrm{LB}+\mathrm{LD} \cdot \mathrm{LB}^{\prime}\right)$, will be the focus of our further discussion and we shall call it simply LDLB. In the past its was also referred to as "pseudo $C D$ " ${ }^{[23]}$ It is independent of instrumental faults and it represents a real differential absorption of left- and right CP-light; it is invariant upon sample rotation around the optical axis, but it inverts upon flipping the sample by $180^{\circ}$ with respect to the optical axis. ${ }^{[24]}$ Theoretically this term is well understood, ${ }^{[25]}$ and experimental evidence of the LDLB effect on a thin polymeric film was first reported for an achiral polyvinyl alcohol (PVA) film dyed with the achiral azo-compound Congo Red and highly stretched in order to make it macroscopically anisotropic. ${ }^{[21]}$ More recently, Craig et al. reported a noticeable variation of extraordinarily large $g$-factor in films of a chiral polyfluorene, strongly depending on the film thickness and on the annealing condition. Their polyfluorene gives a mesotropic phase between 90 and $200^{\circ} \mathrm{C}$, and the films were annealed at $150^{\circ} \mathrm{C}$, i.e. in the middle of the liquid crystalline phase. The authors attributed the large $g$-factors to pseudo CD, which in our terms would be LDLB, although they did not report the simple experiment of sample flipping. ${ }^{[23]} \mathrm{A}$ similar effect of interference between linear dichroism and linear birefringence was also described by Merten et al. in vibrational circular dichroism (VCD) spectra. ${ }^{[26]}$

Very recently we came across the new benzo[1,2-b:4,5$b$ ]dithiophene (BDT)-based oligothiophene 1 bearing two chiral (S)-3,7-dimethyl-1-octyl chains, investigating its supramolecular organization in the solid state through (chiro)optical spectroscopies. Surprisingly, thin films prepared by drop-casting revealed a remarkable LDLB term (at least one order of magnitude larger than $C D_{\text {iso }}$ ), responsible for the inversion of very large ECD signals upon sample flipping. ${ }^{[27]}$

The ECD signal inversion by sample flipping due to a large LDLB term is very appealing: it allows one to obtain opposite chiroptical properties with one chiral material, simply considering the two different faces of the same thin film. In other words one simulates the behavior of optical antipodes with one enantiomer. Therefore, the ability to reproducibly and consistently prepare materials with high LDLB looks extremely promising, especially to obtain devices able to discriminate the direction of sample illumination, if from front or from back. Indeed, our LDLB samples behave as the spectroscopic equivalent of playing heads and tails, i.e. of distinguishing which of the two sides of the film is face up or down.

Starting from these promising considerations, we decided to extend our previous work ${ }^{[27]}$ with a more systematic study on the impact of LDLB in thin films of chiral oligothiophenes depending on their chemical structure, by changing to some extent the chiral chains and the $\pi$-conjugated backbone.

However, a more important aspect to investigate is the influence of deposition technique: on the one hand drop casting is generally performed with a slow solvent evaporation and it hardly produces homogeneous films; on the other hand, spin coating results in a fast deposition, where solution is very quickly spread on a thin layer, from which the solvent immediately evaporates. ${ }^{[28]}$ It is well known that hydrodynamic forces in stirred solutions (i.e. flow vortices) can induce chirality in supramolecular species of $J$-aggregates. ${ }^{[29-36]}$ Therefore, the spin coating technique can play a fundamental role in generating chiroptical properties of thin films: Aida et al. found two enantiomeric supramolecular architectures, resulting in opposite
ECD spectra, for film samples of dendritic zinc porphyrin $J$ aggregates depending on spinning direction. ${ }^{[37]}$ More recently, the same behaviour was found for spin-coated polyaramide films, when the original solution would consist in a lyotropic liquid crystalline phase, although no ECD was recorded upon spin coating an isotropic solution. ${ }^{[38]}$ Unfortunately, in most of the cases cited above, the simple test of sample flipping was not reported.

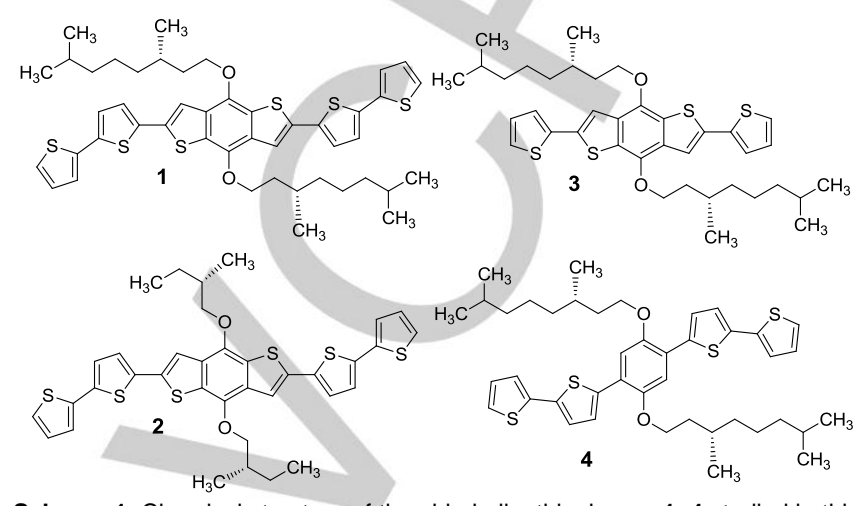

Scheme 1. Chemical structure of the chiral oligothiophenes 1-4 studied in this work.

Here we examined a set of four chiral oligothiophenes 1-4 (Scheme 1), studying their chiroptical features in thin films prepared by drop casting or spin coating and separating true ECD from LDLB. At first, we compared our previous results of drop-casted films of $\mathbf{1}$ with the ones obtained for spin-coated samples, discovering a clear effect of the spin coating deposition on the LDLB term. We then investigated how the position of stereogenic center on the alkyl chain or simply the oligothiophene length may affect the ECD response, studying two new chiral BDT-based oligothiophenes: 2, bearing two (S)-2methyl-1-butyl groups (instead of the (S)-3,7-dimethyl-1-octyl chains present in $\mathbf{1}$ ), and $\mathbf{3}$, differing from $\mathbf{1}$ for the $\pi$-conjugated backbone. As expected, these small structural changes caused very different chiroptical behaviour, with "genuine" ECD features (i.e. independent of sample rotation or flipping) or a remarkable LDLB contribution, depending on the deposition technique. An alternative way for cutting away two thiophene units consists in replacing the 4,8-dialkyloxy BDT central ring with the 1,4dialkyloxyphenylene, which has the merit of simplifying the oligothiophene synthesis. Thin film samples of the new chiral oligomer 4, prepared by drop casting display genuine ECD; on the contrary, samples prepared by spin coating displayed such an extremely large LDLB effect.

\section{Results and Discussion}

\section{Synthesis of the new chiral oligothiophenes 2-4}

The preparation of $\mathbf{1}$, as well as of the opposite enantiomer ent1, was reported in our previous publication. ${ }^{[27]}$ The synthetic pathway of the new chiral oligothiophenes 2-4 is depicted in Scheme 2. 
<smiles>[R]Oc1c2ccsc2c(O[R])c2ccsc12</smiles>

8<smiles>CC[C@H](C)COc1c2cc(-c3ccc(-c4cccs4)s3)sc2c(OC[C@H](C)CC)c2cc(-c3ccc(-c4cccs4)s3)sc12</smiles>

b)<smiles></smiles><smiles>[R]C(C)=CC(C)CC</smiles>

(93\%)
$9 \mathrm{R}=\mathrm{C}_{\mathrm{CH}_{3}}^{\mathrm{CH}_{3}}(77 \%)$

9

d)<smiles>CC1(C)OB(c2cccs2)OC1(C)C</smiles><smiles>CC(C)CCC[C@H](C)CCOc1c2cc(-c3cccs3)sc2c(OCC[C@H](C)CCCC(C)C)c2cc(-c3cccs3)sc12</smiles><smiles>Oc1ccc(O)cc1</smiles>

e)<smiles>[R]Oc1ccc(OC)cc1</smiles>
f)<smiles>[R]C1CCCC1</smiles><smiles>C1CCCC1</smiles><smiles>[R]Oc1cc(I)c(I)cc1I</smiles>

12<smiles>[R]=CC(C)CCC(C)CCCC(C)C</smiles><smiles>C#CC</smiles><smiles>CCCC(C)C(C)CCCC(C)C</smiles>

\section{4}<smiles>CC(C)CCC[C@H](C)CCO</smiles>

Scheme 2. Synthesis of new chiral oligothiophenes 2-4. Conditions: a) R-Br (2.5 eq.), $\mathrm{K}_{2} \mathrm{CO}_{3}\left(10.0\right.$ eq.), $18-\mathrm{crown}^{-6}$ (1 mol\%), $\mathrm{CH}_{3} \mathrm{CN}$, reflux, $30 \mathrm{~h}$; b) $n$-BuLi (2.3 eq.), $\mathrm{CBr}_{4}$ (2.6 eq.), THF, $3.5 \mathrm{~h},-78^{\circ} \mathrm{C} \rightarrow$ r.t.; c) 10 (6.0 eq.), $\mathrm{K}_{2} \mathrm{CO}_{3}$ (ecc.), $\mathrm{Pd}\left(\mathrm{PPh}_{3}\right)_{4}(5 \mathrm{~mol} \%), 1,4$-dioxane, $\mathrm{H}_{2} \mathrm{O}$, reflux, 96 h; d) 11 (6.0 eq.), $\mathrm{K}_{2} \mathrm{CO} \mathrm{O}_{3}$ (ecc.), $\mathrm{Pd}\left(\mathrm{PPh}_{3}\right)_{4}(5 \mathrm{~mol} \%), 1$, -dioxane, $\mathrm{H}_{2} \mathrm{O}$, reflux, $96 \mathrm{~h}$; e) 12 (2.5 eq.), $\mathrm{K}_{2} \mathrm{CO}_{3}$ (10.0 eq.), 18-crown-6 (0.5 mol\%), $\mathrm{CH}_{3} \mathrm{CN}$, reflux, 96 h; f) $\mathrm{I}_{2}$ (1.1 eq.), $\mathrm{KIO}{ }_{3}$ (0.4 eq.), $\mathrm{AcOH}, \mathrm{H}_{2} \mathrm{SO}_{4}$ (10 wt.\%), 24 h, reflux; g) 10 (5.0 eq.), $\mathrm{K}_{2} \mathrm{CO}_{3}$ (ecc.), $\mathrm{Pd}\left(\mathrm{PPh}_{3}\right)_{4}$ (5 mol\%), 1,4-dioxane, $\mathrm{H}_{2} \mathrm{O}$, reflux, $48 \mathrm{~h}$.

Benzo[1,2-b:4,5- $\left.b^{\prime}\right]$ dithiophen-4,8-diol (5), obtained via a four step sequence, according to our previous work, ${ }^{[27]}$ was converted into the corresponding dialkylated products 6 and 7 (63\% and $93 \%$ yield, respectively) by nucleophilic substitution reactions with a slight excess of the chiral bromide $((S)-2$ methyl-1-bromobutane ${ }^{[39]}$ or (S)-3,7-dimethyl-1-bromooctane ${ }^{[40]}$ ) in heterogeneous conditions, using $\mathrm{K}_{2} \mathrm{CO}_{3}$ as base, 18-crown-6 as phase-transfer catalyst and $\mathrm{CH}_{3} \mathrm{CN}$ as solvent. The lower yield of $\mathbf{6}$ is probably due to the higher steric hindrance of reactive site in the $(S)$-2-methyl-1-bromobutane. The following bromination step was performed in alkaline conditions with $n$ BuLi and $\mathrm{CBr}_{4}$, affording 8 and 9 with good yield (82\% and $77 \%$, respectively). Finally, Suzuki-Miyaura cross-coupling reaction of 8 with an excess of boronic ester 10, performed using a new optimised protocol $\left(\mathrm{Pd}\left(\mathrm{PPh}_{3}\right)_{4}, \mathrm{~K}_{2} \mathrm{CO}_{3}\right.$, 1,4-dioxane, $\mathrm{H}_{2} \mathrm{O}$, reflux), yielded final oligothiophene 2 (30\% of yield), while the reaction of 9 with boronic ester 11 under the same experimental conditions gave oligothiophene $\mathbf{3}$ with significantly higher yield (60\%).

The chiral oligothiophene 4 was more easily synthesized in a three-steps pathway: commercial hydroquinone (12) was alkylated with (S)-3,7-dimethyl-1-bromooctane under the same protocol used for the BDT-derivative 5 (i.e. $\mathrm{K}_{2} \mathrm{CO}_{3}$ and 18-crown6 in acetonitrile), affording the corresponding dialkylated product 13 (78\% yield), which was subsequently iodurated with $\mathrm{I}_{2} / \mathrm{KIO}_{3}$ to give 14 (67\% yield). Finally, Suzuki-Miyaura coupling (under the same optimized conditions) with an excess of boronic ester $\mathbf{1 0}$ gave oligothiophene 4 with good yield (80\%). Similarly, we also prepared the opposite enantiomer ent-4 starting from $(R)-3,7-$ dimethyl-1-bromooctane.

\section{Optical and chiroptical properties of chiral oligothiophenes 1-4}

We started from the oligothiophene 1, partially investigated in our previous work. ${ }^{[27]}$ At first, we prepared again thin films of 1 by drop casting (DC-1), depositing on a quartz plate $100 \mu \mathrm{L}$ of a $1.0 \cdot 10^{-3} \mathrm{M}$ solution in $\mathrm{CH}_{2} \mathrm{Cl}_{2}$, followed by slow evaporation of the solvent in a closed chamber saturated with $\mathrm{CH}_{2} \mathrm{Cl}_{2}$ vapours. The ECD spectrum (Figure 1a) was the same described previously, ${ }^{[27]}$ i.e. with $\mathrm{CD}$ signals almost perfectly inverted by sample flipping: dissymmetry $g$-factor value at $300 \mathrm{~nm}=1.8 \times$ 

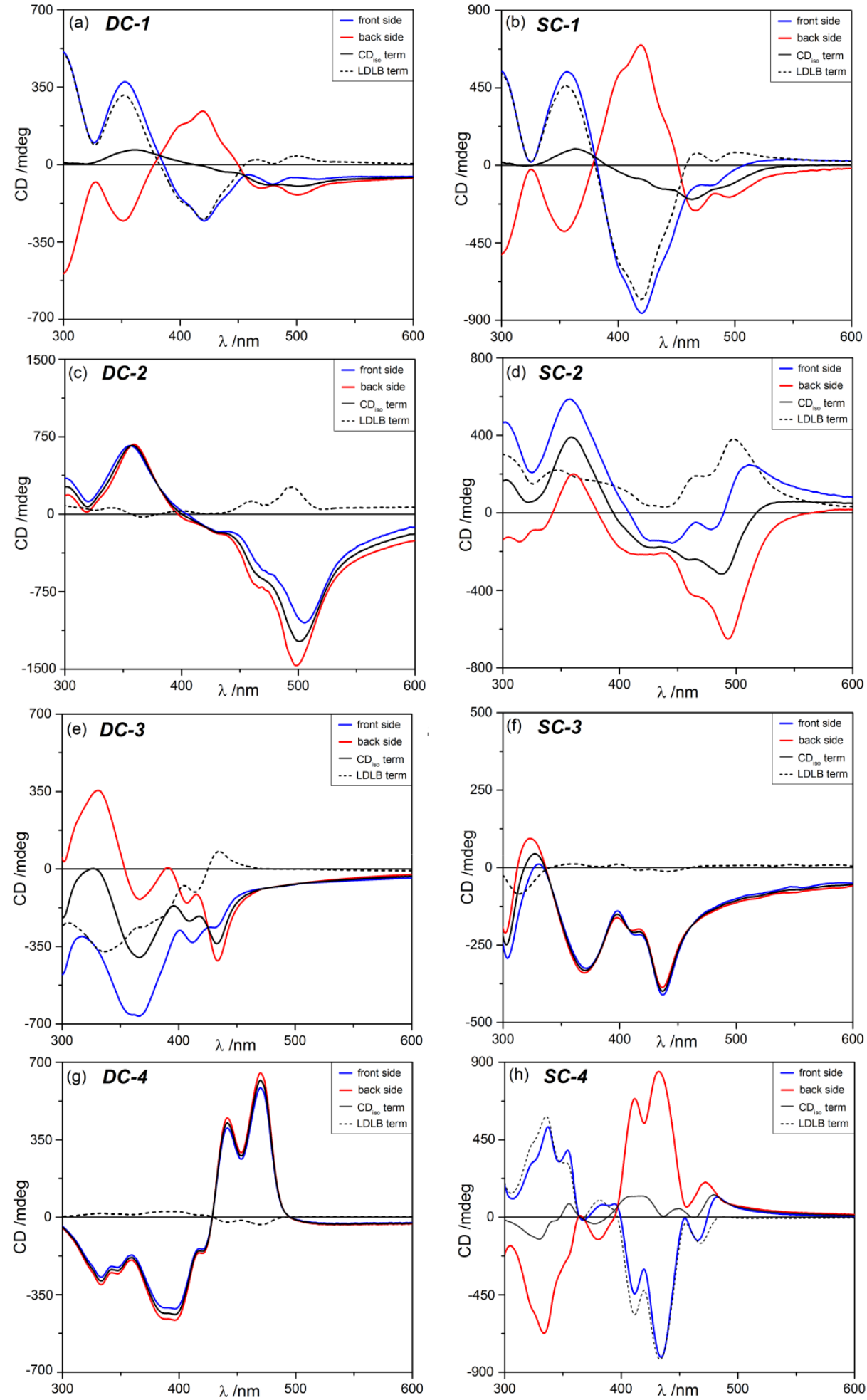

Figure 1. ECD spectra (normalized with respect to maximum absorbance) for the front side (blue line) and back side (red line) of chiral oligothiophenes 1-4 as

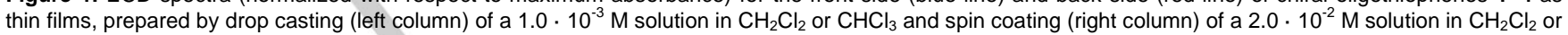
$\mathrm{CHCl}_{3}$ with angular speed of 1000 rpm: (a) DC-1; (b) SC-1; (c) DC-2; (d) SC-2; (e) DC-3; (f) SC-3; (g) DC-4; (h) SC-4. For each panel, black continuous line is the $\mathrm{CD}_{\text {iso }}$ term, while black dashed line the LDLB term.

$10^{-2}$ for the front, i.e. with the organic film facing the light source, and $-1.8 \times 10^{-2}$ for the back, i.e. with the organic layer facing the detector (Table 1, entry 1 ).

Following Mueller matrix analysis recalled above, ${ }^{[18-20]}$ the described properties ruled out the third term of Eq. (2) (and actually all other higher order terms, as well), demonstrating that total LD is small, but on the contrary a massive LDLB contribution. We can isolate the $C D_{\text {iso }}$ and LDLB terms by taking semi-sum and semi-difference of the two spectra recorded with the two sample orientations, i.e. front and back.

$$
C D_{\text {iso }}=0.5 \times\left(E C D_{\text {front }}+E C D_{\text {back }}\right)(3)
$$$$
\mathrm{LDLB}=0.5 \times\left(E C D_{\text {front }}-E C D_{\text {back }}\right)(4)
$$ 
Table 1. Chiroptical properties of thin films studied in this work: maximum $g$ factor value (together with their corresponding wavelengths) recorded for both front and back side of each sample.

\begin{tabular}{cccccc}
\hline \multirow{2}{*}{ Entry } & \multicolumn{2}{c}{ Sample } & \multicolumn{2}{c}{ Front side } & \multicolumn{2}{c}{ Back side } \\
& & $\lambda_{\max }(\mathrm{nm})$ & $g_{\max }$ & $\lambda_{\max }(\mathrm{nm})$ & $g_{\max }$ \\
\hline 1 & DC-1 & 300 & $+1.8 \times 10^{-2}$ & 300 & $-1.8 \times 10^{-2}$ \\
2 & SC-1 & 420 & $-2.8 \times 10^{-2}$ & 420 & $+2.2 \times 10^{-2}$ \\
3 & DC-2 & 505 & $-5.5 \times 10^{-2}$ & 498 & $-6.8 \times 10^{-2}$ \\
4 & SC-2 & 365 & $+3.3 \times 10^{-2}$ & 495 & $-2.2 \times 10^{-2}$ \\
5 & DC-3 & 370 & $-2.0 \times 10^{-2}$ & 330 & $+1.9 \times 10^{-2}$ \\
6 & SC-3 & 440 & $-1.5 \times 10^{-2}$ & 440 & $-1.5 \times 10^{-2}$ \\
7 & DC-4 & 470 & $+1.7 \times 10^{-2}$ & 470 & $+1.9 \times 10^{-2}$ \\
8 & SC-4 & 436 & $-2.7 \times 10^{-2}$ & 436 & $+2.8 \times 10^{-2}$ \\
\hline
\end{tabular}

The result of these operations are depicted in Figure 1a, displaying a LDLB term (black dashed line) significantly larger than $\mathrm{CD}_{\text {iso }}$ (black continuous line): for this reason at first sight the experimental ECD spectrum practically becomes inverted upon flipping the sample. A more quantitative comparison between $C D_{\text {iso }}$ and LDLB contribution to the experimental ECD signal was obtained considering the area of absolute value of spectra semisum and semi-difference (Table 2 , entry 1 ): these values $(\approx$ 10900 and 21900 , respectively) confirmed that LDLB term is about double compared to $\mathrm{CD}_{\text {iso }}$.

As well known, spin coating is a more appropriate tool for producing homogeneous thin film sample. In our case, the solvent immediately evaporates, being it $\mathrm{CH}_{2} \mathrm{Cl}_{2}$. We prepared thin films of $\mathbf{1}$ by spin coating (SC-1) depositing on a quartz plate $\sim 100 \mu \mathrm{L}$ of a $2.0 \cdot 10^{-2} \mathrm{M}$ solution in $\mathrm{CH}_{2} \mathrm{Cl}_{2}$ with angular speed of $1000 \mathrm{rpm}$. The UV-Vis absorption spectrum (see Figure S1 in Supporting Information) showed a very similar profile to the one observed in our previous work ${ }^{[27]}$ for DC-1: the main bands fell in the range between $350 \mathrm{~nm}$ and $500 \mathrm{~nm}$ (maximum at $440 \mathrm{~nm}$ ), and a significant baseline drift due to light scattering was observed at long wavelengths. More surprisingly, also chiroptical features of SC-1 (Figure 1b) revealed a similar trend to DC-1: the ECD profiles became almost perfectly inverted by sample flipping, with a consistent match of shapes with DC-1 for both front and back, but stronger intensity. The maximum $g$-factor value, recorded at $420 \mathrm{~nm}$, was $-2.8 \times 10^{-2}$ for the front side and $2.2 \times 10^{-2}$ for the back side (Table 1 , entry 2 ). Similar to that described for DC-1 in our previous work, ${ }^{[27]}$ the behaviour of SC1 was reproducible by re-preparing 5 separate samples. As further control, we performed the same measurement on the opposite enantiomer ent-1 (Figure S2). The ECD spectra of spin-coated thin films of ent-1 revealed, although with an inverted behaviour to 1 , the same phenomenon of ECD inversion by sample flipping (Figure S3). These experiments demonstrate the optimal quality of spin-coated films on one hand but they also reveal that the LDLB effect can by no means be regarded as an artifact.

The occurrence of these chiroptical features in SC-1 was quite unexpected. In particular, considering the area of absolute value of semi-sum and semi-difference (Table 2, entry 2 ), the $C D_{\text {iso }}$ term was found to be almost equal to that of DC-1 (i.e. 14700 of
SC-1 vs. 10900 of DC-1), while the LDLB contribution was significantly higher (i.e. 63600 for SC-1 vs. 21900 for DC-1), then resulting in a $L D L B / C D_{\text {iso }}$ ratio of 4.33 . At first, these results suggest that the supramolecular order is reached here in the short time required for solvent evaporation. A slightly more indepth consideration is that the amplitude of LDLB is indeed much larger with spin coating than with drop casting, then suggesting a more intriguing role played by sample spinning. It is also worth recalling that no solvent or thermal annealing was applied to our films so far.
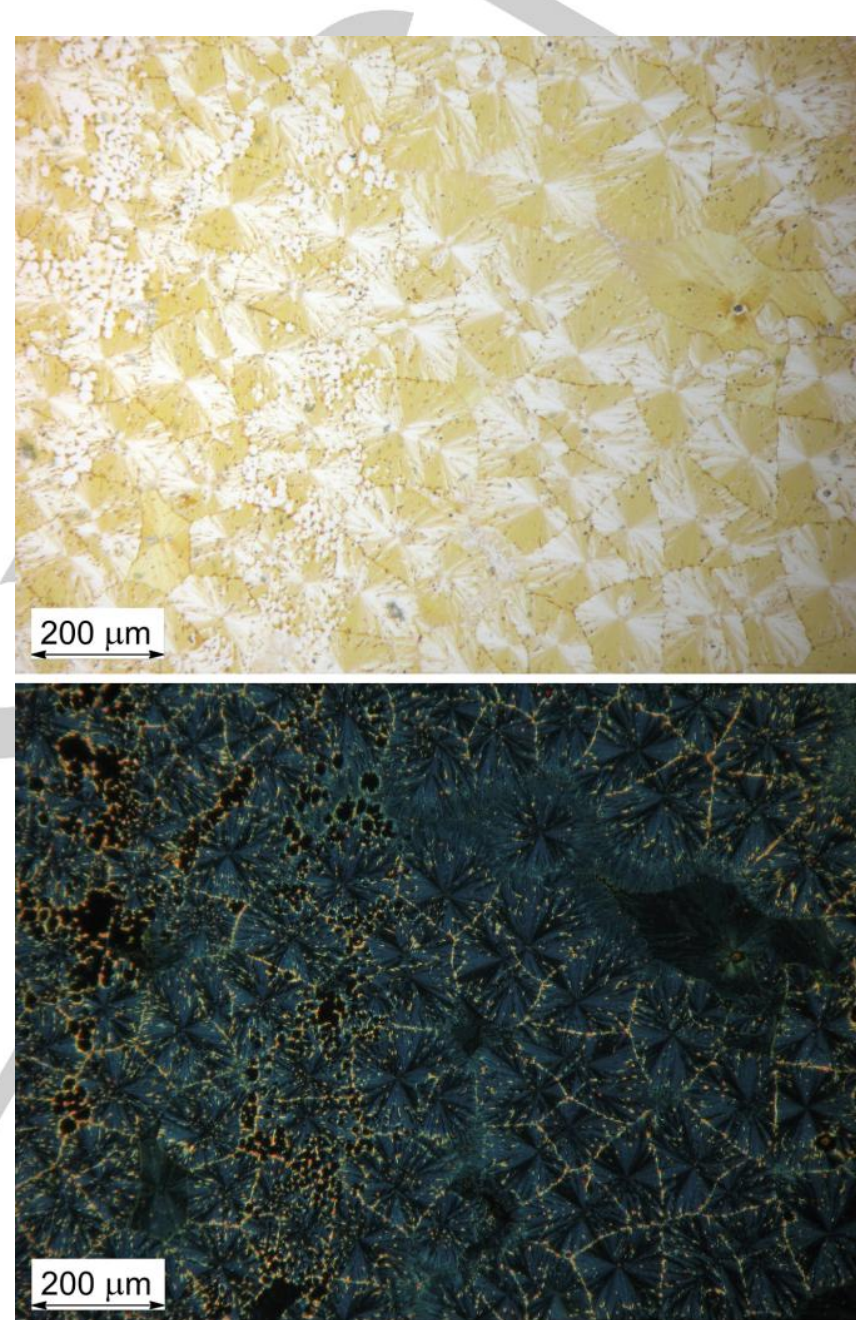

Figure 2. Optical microscopy images of SC-1 sample: micrograph with nonpolarized light (up); micrograph under cross-polarized filters (down).

Optical and polarized optical microscopy (POM) images of SC-1 are shown in Figure 2. They clearly reveal domains of about 0.1 $\mathrm{mm}$ diameter with some degree of birefringence, which is in accord to the schematic picture we had put forward for DC-1 samples in our previous investigation. ${ }^{[27]}$

The LDLB effect described above for DC-1 and SC-1 thin films is a very appealing property, which in theory can be exploited for the realization of new optoelectronic devices, able to discriminate the direction of sample illumination. Attracted by the idea of obtaining materials with even higher ECD signals, that can be inverted by sample flipping, we decided to investigate the impact of LDLB effect depending on the oligothiophene structure. A first possible variation in the chemical structure consists in changing the position of methyl group (and also of the chiral centre, of course) on the alkyl chain. For this purpose, we 
focused our attention on the new BDT-based oligothiophene 2, which differs from 1 for the presence of two (S)-2-methyl-1-butyl groups (instead of the (S)-3,7-dimethyl-1-octyl chains).

We prepared samples of 2 by drop casting (DC-2) under the same conditions $\left(100 \mu \mathrm{L}\right.$ of a $1.0 \cdot 10^{-3} \mathrm{M}$ solution of 2 in $\mathrm{CH}_{2} \mathrm{Cl}_{2}$, followed by slow evaporation of the solvent in atmosphere saturated with $\mathrm{CH}_{2} \mathrm{Cl}_{2}$ vapours). The UV-Vis spectrum (Figure S4) revealed a roughly similar profile to that recorded in solution, with a wider band between 325 and $600 \mathrm{~nm}$ centred at around $450 \mathrm{~nm}$. Unlike DC-1 samples, however, the ECD spectrum (Figure 1c) revealed almost standard behaviour: it was to a good extent invariant by sample flipping, with good match between front and back side. The maximum $g$-factor value, recorded at around $500 \mathrm{~nm}$, was $-5.5 \times 10^{-2}$ for the front side and $-6.8 \times$ $10^{-2}$ for the back side (Table 1 , entry 3 ). Therefore, in DC-2 samples the LDLB effect was negligible, resulting in a LDLB/CD iso ratio of 0.15 (Table 2, entry 3 ).

Thin film samples of 2 prepared by spin coating (SC-2) of a 2.0 . $10^{-2} \mathrm{M} \mathrm{CH}_{2} \mathrm{Cl}_{2}$ solution revealed a behaviour similar to $\mathbf{D C}-2$ in the UV-Vis absorption (Figure S5) but not in the ECD: in this case spectra recorded for the front and the back were quite different, although not mirror image like in DC-1 and SC-1: the maximum $g$-value was $3.3 \times 10^{-2}$ (at $365 \mathrm{~nm}$ ) for the front, -2.2
Table 2. Integral areas of the absolute value of $C D_{\text {iso }}$ and LDLB for thin film samples studied in this work calculated between 300 and $600 \mathrm{~nm}$.

\begin{tabular}{|c|c|c|c|c|}
\hline Entry & Sample & $\begin{array}{c}\text { Integral of } \\
\left|C D_{\text {iso }}\right|\end{array}$ & $\begin{array}{c}\text { Integral of } \\
\mid \text { LDLB } \mid\end{array}$ & $\begin{array}{c}\text { Ratio } \\
\int|\operatorname{LLLB}| / \int\left|\mathrm{CD}_{\text {iso }}\right|\end{array}$ \\
\hline 1 & DC-1 & 10900 & 21900 & 2.01 \\
\hline 2 & SC-1 & 14700 & 63600 & 4.33 \\
\hline 3 & DC-2 & 126250 & 19500 & 0.15 \\
\hline 4 & SC-2 & 44400 & 45800 & 1.03 \\
\hline 5 & DC-3 & 40900 & 31750 & 0.78 \\
\hline 6 & SC-3 & 46200 & 3750 & 0.08 \\
\hline 7 & U & 56100 & 3250 & 0.06 \\
\hline 8 & SC-4 & 13300 & 58100 & 4.37 \\
\hline
\end{tabular}
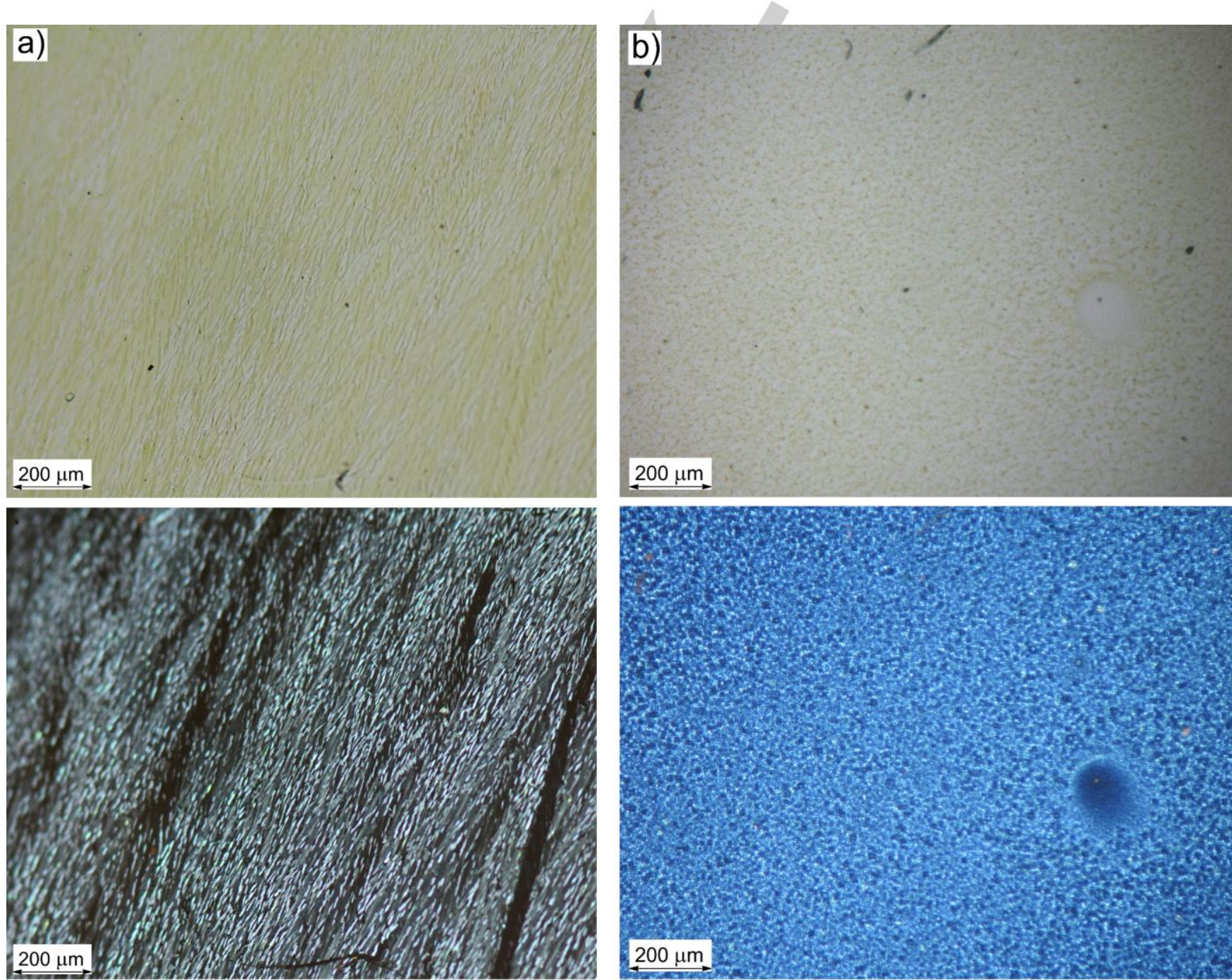

Figure 3. Optical microscopy images of DC-4 (a) and SC-4 (b) samples: micrograph with non-polarized light (up); micrograph under cross-polarized filters (down) 
$\times 10^{-2}$ (at $495 \mathrm{~nm}$ ) for the back (Table 1 , entry 4$)$. We isolated $\mathrm{CD}_{\text {iso }}$ and LDLB terms by taking semi-sum and semi-difference, displaying that they are comparable: in fact, the integral area of their absolute values were 44400 and 45800 respectively, with a $\mathrm{LDLB} / \mathrm{CD}_{\text {iso }}$ ratio of 1.03 (Table 2 , entry 4 ). Interestingly, the shapes of semi-sum and semi-difference in SC-2 seem very similar to the ones found in $\mathbf{D C}-\mathbf{2}$, though with different intensities: passing from drop casting to spin coating technique, a decrease of the $C D_{\text {iso }}$ term in favour of the LDLB term was observed. We can hypothesize that $C D_{\text {iso }}$ and LDLB are here the expression of two different chiral supramolecular organization of 2, both present in thin film samples, but with different contributions depending on the deposition technique. Therefore, spin coating revealed again a very crucial role in amplifying the impact of LDLB effect in thin films of chiral oligothiophenes.

A different approach for modifying the chemical structure of these systems is to change the length of the $\pi$-conjugated backbone: this parameter allows one to shift the optical chiroptical signals to longer or shorter wavelengths. Therefore, we passed on to study the oligomer $\mathbf{3}$, which is shorter than $\mathbf{1}$ by two thiophene units.

We first prepared samples of $\mathbf{3}$ by drop casting (DC-3) of a 1.0 $\cdot 10^{-3} \mathrm{M} \mathrm{CH}_{2} \mathrm{Cl}_{2}$ solution. The UV-Vis absorption spectrum (Figure S6), as expected, is blue-shifted with respect to the corresponding ones of compounds $\mathbf{1}$ and $\mathbf{2}$, on account of the shorter conjugation length: the main band falls between 310 and $440 \mathrm{~nm}$, with maximum at $360 \mathrm{~nm}$. The ECD (Figure 1e) featured somewhat different front and back side profiles resulting in comparable contributions from LDLB and $\mathrm{CD}_{\text {iso }}$ with a global $\mathrm{LDLB} / C D_{\text {iso }}$ ratio of 0.78 (Table 2 , entry 5 ).

Thin films of the oligothiophene $\mathbf{3}$ prepared by spin coating (SC3) under the above-mentioned conditions (i.e. $100 \mu \mathrm{L}$ of a 2.0 $10^{-2} \mathrm{M}$ solution in $\mathrm{CH}_{2} \mathrm{Cl}_{2}$ with angular speed of $1000 \mathrm{rpm}$ ), whose UV-Vis absorption spectrum (Figure S7) was roughly similar to the one of DC-3, revealed unexpected chiroptical features. Unlike samples SC-1 and SC-2, indeed, the ECD spectrum of SC-3 (Figure 1f) was found invariant upon sample flipping, with a perfect match of signs and intensities of bands recorded for the two film orientations $\left(g_{\max }=-1.5 \times 10^{-2}\right.$ at $440 \mathrm{~nm}$, Table 1 , entry 6 ). Consequently, it can be considered an ideal case of pure of $C D_{\text {iso }}$, with $L D L B / C D_{\text {iso }}$ ratio of 0.08 (Table 2, entry 6 ). The behaviour is fully reproducible, as confirmed by re-preparing 5 separate thin films of SC-3. The ECD spectrum of SC-3 is very similar (both in shape and intensity) to the semi-sum profile found in DC-3 samples. We can hypothesize again that $C_{\text {iso }}$ and LDLB terms are the expression of two different chiral supramolecular organization of oligothiophene 3 : in films prepared by drop casting they are both present, with a slight prevalence of that associated with $C D_{\text {iso }}$ (in fact $L D L B / C D_{\text {iso }}$ is 0.78 , Table 2, entry 5) which is instead the only one in spin-coated samples.

The chiral oligothiophene 4 contains as central core a 1,4dialkyloxyphenylene unit (instead of 4,8-dialkyloxy BDT) decorated with two (S)-3,7-dimethyl-1-octyloxy groups: it can be considered an alternative way for decreasing the $\pi$-conjugated chromophore length by two thiophene units.

We prepared thin films of $\mathbf{4}$ by drop casting (DC-4) using $~ 100$ $\mu \mathrm{L}$ of a $1.0 \cdot 10^{-3} \mathrm{M}$ solution in $\mathrm{CHCl}_{3}$ (which was found a better solvent than $\mathrm{CH}_{2} \mathrm{Cl}_{2}$ ). The morphology was observed by means of standard optical microscopy (Figure 3a): we clearly observed a long-range ordered structure, with rod-like microdomains (average length around $25 \mu \mathrm{m}$ ) collectively oriented in the direction of their main axis. The polarized optical microscopy (POM) revealed birefringent domains on a black background, i.e. with no linear birefringence. The UV-Vis absorption spectrum (Figure S8) showed the main band centred at $436 \mathrm{~nm}$ and characterized by an evident vibronic structure; a pronounced baseline drift was also observed at long wavelengths due to scattering, possibly associated with the birefringent short-range ordered domains observed though POM.

The ECD spectrum of DC-4 is shown in Figure $1 \mathrm{~g}$ : the maximum $g$, found at $470 \mathrm{~nm}$, was $1.7 \times 10^{-2}$ for the front and $1.9 \times 10^{-2}$ for the back (Table 1, entry 7 ). Therefore, the spectrum was invariant by sample flipping and the $L D L B / C D_{\text {iso }}$ ratio was 0.06 (Table 2, entry 7 ), proving that LDLB term was totally negligible. For this reason, we can consider the ECD spectrum in Figure $1 \mathrm{~g}$ a "true $C D$ " of this aggregated state of 4 .

After preparing thin film samples of 4 by spin coating (SC-4) using $\sim 100 \mu \mathrm{L}$ of a $2.0 \cdot 10^{-2} \mathrm{M} \mathrm{CHCl}_{3}$ solution with angular speed of 1000 rpm, we obtained a UV-Vis absorption spectrum (Figure S9) quite similar to DC-4, associated with very strong ECD signals, attaining a $g$-factor of $-2.7 \times 10^{-2}$ at $436 \mathrm{~nm}$ (Table 1, entry 8). The ECD spectrum (Figure $1 \mathrm{~h}$ ) is almost perfectly inverted by flipping, resulting in a $L D L B / C D_{\text {iso }}$ ratio of 4.37 (Table 2, entry 8 ). We must underline that the situation is completely reproducible upon re-preparing 5 different samples. Moreover, spin coated thin films of the opposite enantiomer ent4 provided ECD spectra exactly mirror images to SC-4 sample (Figure S10), revealing the total reproducibility of our results even on re-starting from the very beginning of the compound synthesis and using a completely independent chiral material.

While conventional optical microscopy of SC-4 showed a uniform film texture, POM revealed an homogeneous blue hue instead of the expected dark field, which indicates a strong LB at the higher energy end of the visible spectrum (Figure $3 b$ ). Interestingly, this colour does not change upon rotating the sample with respect to the polarizer, suggesting that the thin film consists of birefringent domains, well below the optical microscope resolution.

In the thin films of BDT-based oligothiophenes 1-3 described above, although in general we observed a variation of $L D L B / C D_{\text {iso }}$ ratio switching from drop casting to spin coating, the shapes of $C D_{\text {iso }}$ and LDLB remained almost the same. This suggested the coexistence of two distinct orders of chiral supramolecular organizations: one responsible for $C_{\text {iso }}$, the other one responsible for the LDLB effect, but with different relative contributions depending on chemical structure and deposition technique. On the contrary, in SC-4 the shape of $C D_{\text {iso }}$ is completely different from the one found in DC-4: this reveals that the intrinsic chirality of the aggregates may be different in the two forms of deposition technique.

In order to better reveal the impact of sample spinning in spin coating preparations, we deposited a much larger sample of SC4 on a $2.5 \times 6 \mathrm{~cm}$ microscopy glass plate and measured the ECD spectrum as a function of the distance from the centre (i.e. where the spin coater tip is located). The results are depicted in Figure $S 11$ : while $C D_{\text {iso }}$ contribution remains rather constant, the LDLB term increases with the distance from the centre. We are not able to provide any further precision, because in this experiment the ECD spectrum is sampled on a wide area of about $1 \mathrm{~cm}$ diameter, which is not at all negligible, compared to the distance from centre. We can conclude that the shear stress of the SC-4 sample favours the LDLB effect but it plays only a small role on the intrinsic chirality represented by $C D_{\text {iso }}$. 
Table 3. Integral areas of the absolute value of $C D_{\text {iso }}$ and LDLB for SC-4 samples prepared with different spinning rate calculated between 300 and 600 $\mathrm{nm}$.

\begin{tabular}{ccccc}
\hline Entry & $\begin{array}{c}\text { Spinning } \\
\text { rate }(\mathrm{rpm})\end{array}$ & $\begin{array}{c}\text { Integral of } \\
\left|\mathrm{CD}_{\text {iso }}\right|\end{array}$ & $\begin{array}{c}\text { Integral of } \\
|\mathrm{LDLB}|\end{array}$ & $\begin{array}{c}\text { Ratio } \\
\int|\mathrm{LDLB}| /\left|\mathrm{CD}_{\text {iso }}\right|\end{array}$ \\
\hline 1 & 300 & 53800 & 23600 & 0.44 \\
2 & 700 & 30250 & 22100 & 0.73 \\
3 & 1000 & 13300 & 58100 & 4.37 \\
4 & 2000 & 35300 & 65800 & 1.86 \\
5 & 4000 & 38100 & 67500 & 1.77 \\
\hline
\end{tabular}

An even more stringent proof of the spin coating role in thin films of oligothiophene 4 comes from the spinning rate. We prepared a set of SC-4 samples using different angular speed (i.e. 300 rpm, $700 \mathrm{rpm}, 2000 \mathrm{rpm}, 4000 \mathrm{rpm}$ ), recording for each one the ECD spectra of front and back side (Figure 4). By increasing the rotation speed, the CDiso at first decreases keeping roughly the same shape, but above $1000 \mathrm{rpm}$ it increases again, although with a quite different profile (Figure $5 \mathrm{a}$ ), while the LDLB term increases and reaches a maximum at $4000 \mathrm{rpm}$ always with a similar shape (Figure 5b), with the only exception of the $490 \mathrm{~nm}$ band, which is positive at very low spinning rate and negative from $1000 \mathrm{rpm}$ on. These two different trends are also reflected on the integral area of absolute values of semi-sum and semidifference, revealing that the maximum LDLB/CDiso ratio is obtained right at $1000 \mathrm{rpm}$ (Table 3).
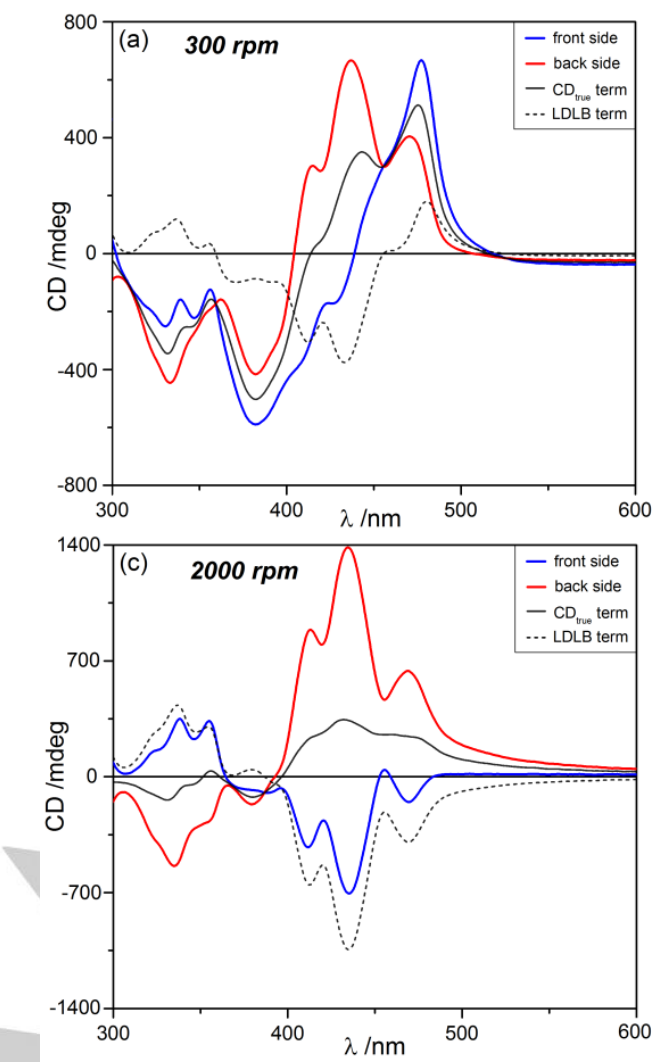

In addition, it is remarkable that even at the very low speed of $300 \mathrm{rpm}$, which is usually regarded as almost equivalent to drop casting, the LDLB is far from negligible (Figure 4a and Table 3, entry 1), while it was totally absent in the drop casted sample DC-4 (Figure $1 \mathrm{~g}$ and Table 2, entry 7). This was also well reflected in POM images, where we observed the same brilliant blue colour found for the more rapid spinning, whereas DC-4 sample appeared very dark. As expected, optical microscopy reveals grains of decreasing size on increasing spinning rate (Figure S12).

In order to further understand the close correlation existing between chiroptical properties and supramolecular organization of drop-casted and spin-coated films of oligothiophene $\mathbf{4}$, we analysed DC-4 and SC-4 samples by means of X-ray diffraction (XRD) technique, as shown in Figure S13. A very low degree of order is generally detected: only in DC-4 a weak peak is barely observed, which d-spacing is close to $1.2 \mathrm{~nm}$, indicating a large molecular stacking, possibly due to the approach of adjacent molecules. This effect is instead unobserved in SC-4. An approximate molecular modelling indicates that an adjacent couple of molecules can approach at a distance less than $1 \mathrm{~nm}$ : on allowing some rotation between molecular axes of nearby molecules, the distance will increase, possibly matching the observed value. Therefore, these results can support the abovedescribed chiroptical features.

Upon extended storage (above a month at room temperature) the LDLB effect slowly yields to a $C D_{\text {iso }}$.
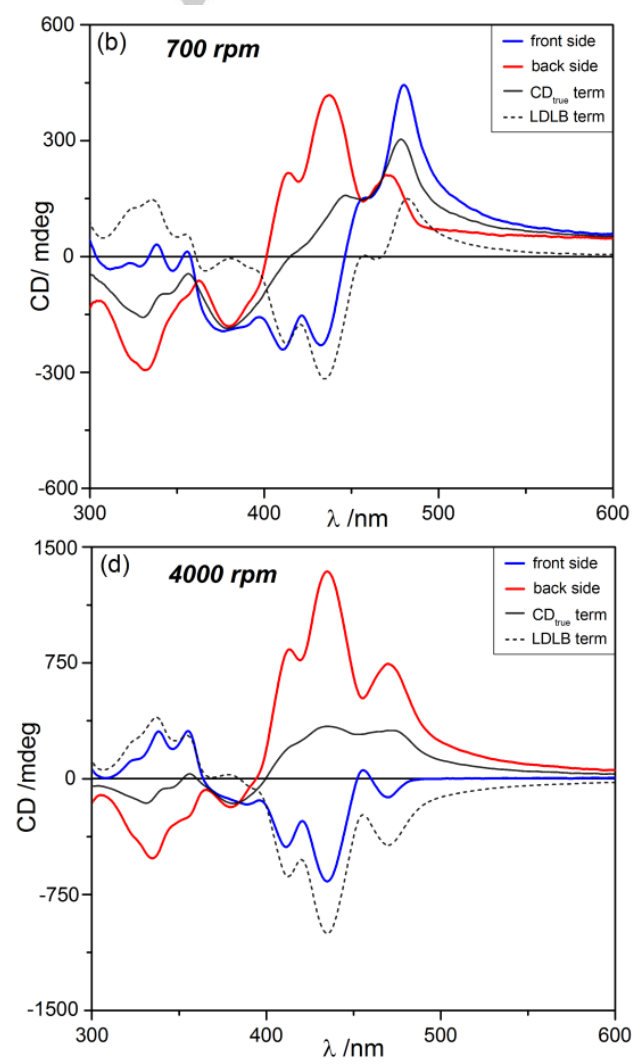

Figure 4. ECD spectra (normalized with respect to maximum absorbance) for the front side (blue line) and back side (red line) of SC-4 samples prepared with different angular speed: (a) $300 \mathrm{rpm}$; (b) $700 \mathrm{rpm}$; (c) $2000 \mathrm{rpm}$; (d) $4000 \mathrm{rpm}$. For each panel, black continuous line is the $C D_{\text {iso }}$ term, while black dashed line the LDLB term. 
Recently, we introduced the concept of CD imaging (CD $I)$, using ECD to map the surface of thin films of chiral organic $\pi$ conjugated systems, thanks to the highly collimated light beam of Diamond Light Source radiation. ${ }^{[41]}$ We revealed that apparently homogeneous films can be characterized by local polymorphisms responsible for different contributions to the emergent ECD spectrum. In the case of the oligothiophene 4, we can interpret the results admitting that, while LDLB is the result of a single species, the $C D_{\text {iso }}$ may be the combination of different aggregated forms, whose relative weight depends on the spinning rate. ${ }^{[42]} \mathrm{A}$ deeper investigation of this behaviour, including by means of $\mathrm{CD} i$ technique is in progress. Following the model we put forward in our previous paper, ${ }^{[27]}$ the LB domains must be characterized by a LD', i.e. by a linear dichroism about a skewed axis with respect to LB. Globally, both linear properties average to 0 , but their product does not and provides a distinct chiroptical signal. This is shown schematically in Figure 6, which represents randomly oriented domains, to be compared for example with the microscopy images of Figure 2, 3 and $\mathrm{S} 12$ : POM highlights LB, while localized information on LD is more difficult to achieve.
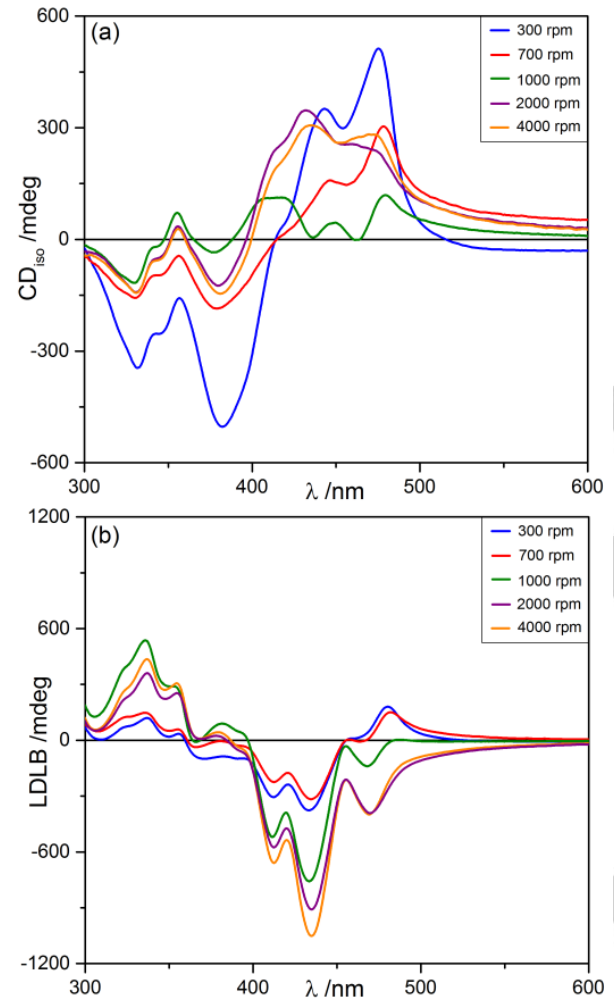

Figure 5. Comparison of $C D_{\text {iso }}$ (a) and LDLB (b) for the ECD spectra (normalized with respect to maximum absorbance) of SC-4 samples prepared with different angular speed).

\section{Conclusions}

We studied a systematic set of thiophene-based oligomers, where we changed the extension of the $\pi$-conjugated backbone and the chiral aliphatic side chain. We demonstrated that these compounds can give rise to a manifold of situations, where the dichroic signals are due either to the intrinsic chirality of the aggregates, which can be the ultimate responsible for an isotropic $C D$, or to the interference between linear dichroism and linear birefringence or LDLB. Although LDLB has been known for decades, it has been generally neglected, when not treated as an undesirable artefact. We suspect that in several cases in the previous literature, especially when dealing with spin coating as the technique to obtain thin films, this effect may have been present, although it has not been clearly reported, because of the lack of the crucial experiment, consisting in sample flipping. We provided a practical toolbox to recognize and quantify the relative weights of true CD and LDLB in organic thin films, by working on a small family of structurally related oligothiophenes. Depending on the molecular structure and on the sample preparation, one can obtain sizable dichroic effects, which will be used for the development of optical sensors responding to circular polarization of light.

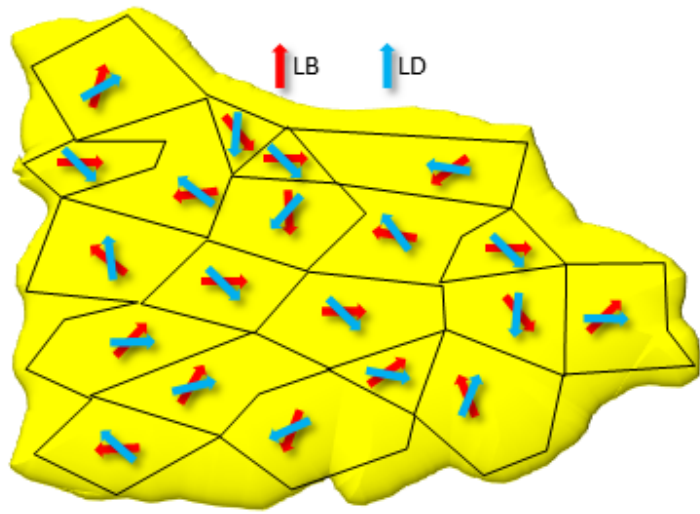

Figure 6. Idealized domains of one of thin film samples giving rise to the LDLB effect. The blue arrows represent the LD principal axis, while the red arrows represents LB principal axis. They are consistently tilted by $-45^{\circ}$ and thus the LDLB term is negative for this representation. The average value of both LD and LB vanishes, on account of the overall sample isotropy.

We became aware that the poorly investigated LDLB effect may have interesting practical fallouts. In the first place, materials endowed with dominant LDLB have the very desirable property of providing mirror image $C D$ effects, by simply flipping the sample. In the case of chiral chromophores, as the ones we considered, one enantiomer provides both CD signs at the same wavelength.

The second outstanding feature is that this allows one to spectroscopically reveal which if the sample is face up (to the light) or down (to the detector): we propose a similarity with heads and tails of a coin.

\section{Experimental Section}

\section{Synthesis}

General. All chemicals were purchased from Sigma Aldrich or Alfa Aesar and used as received without purification. Commercial grade solvents were purified by conventional methods, distilled and stored over activated molecular sieves under nitrogen atmosphere. All the operations under inert atmosphere were carried out using standard Schlenk techniques and employing dried nitrogen. All reactions conversion was monitored by thin-layer chromatography (TLC) analysis on pre-coated silica gel plates ALUGRAM® Xtra SIL G/UV 254 (0.2 mm) purchased from VWR Macherey-Nagel. Column chromatography was performed with Fluka silica gel, pore size $60 \AA$, 70-230 mesh, 63-200 $\mu \mathrm{m} .{ }^{1} \mathrm{H}-\mathrm{NMR}$ and ${ }^{13} \mathrm{C}$ NMR spectra were recorded at room temperature in $\mathrm{CDCl}_{3}$ or $\mathrm{DMSO}-\mathrm{d}_{6}$ solution with a Bruker Avance DRX 400 spectrometer, operating at a frequency of $400 \mathrm{MHz}$ for ${ }^{1} \mathrm{H}$ and $100 \mathrm{MHz}$ for ${ }^{13} \mathrm{C}$, using the residual 
solvent peak as internal reference; chemical shifts $(\delta)$ values are given in parts per million (ppm) and coupling constants $(\mathrm{J})$ in Hertz. Mass spectra were obtained with an Applied Biosystems- MDS Sciex API 4000 triple quadrupole mass spectrometer (Concord, Ont., Canada), equipped with a Turbo-V ion-spray (TIS) source.

\section{4,8-Bis((S)-2-methylbutoxy)benzo[1,2-b:4,5-b']dithiophene}

Benzo[1,2-b:4,5-b']dithiophene-4,8-diol (5) (1.36 g, $6.12 \mathrm{mmol}$ ), (S)-2 methyl-1-bromobutane $(2.30 \mathrm{~g}, 15.25 \mathrm{mmol}), \mathrm{K}_{2} \mathrm{CO}_{3}(8.46 \mathrm{~g}, 61.2 \mathrm{mmol})$, 18-crown-6 (16 mg, $0.061 \mathrm{mmol})$ and $\mathrm{CH}_{3} \mathrm{CN}(135 \mathrm{~mL}$ ) were mixed together. The mixture was refluxed under stirring for $30 \mathrm{~h}$, then it was cooled to room temperature, filtered and the solvent was removed under vacuum. The residue was dissolved in $\mathrm{CH}_{2} \mathrm{Cl}_{2}(50 \mathrm{~mL})$ and washed with $\mathrm{H}_{2} \mathrm{O}(3 \times 50 \mathrm{~mL})$, then the organic phase was dried over anhydrous $\mathrm{Na}_{2} \mathrm{SO}_{4}$ and the solvent was removed under vacuum. The crude product was purified through column chromatography $\left(\mathrm{SiO}_{2}, n\right.$-hexane/ $\mathrm{CH}_{2} \mathrm{Cl}_{2}$ $90: 10 \rightarrow 50: 50)$ to give $6(1.40 \mathrm{~g}$, yield $63 \%)$ as a yellowish oil. ${ }^{1} \mathrm{H}-\mathrm{NMR}$ $\left(\mathrm{CDCl}_{3}\right), \delta(\mathrm{ppm}): 1.05(6 \mathrm{H}, \mathrm{t}, J=7.4 \mathrm{~Hz}), 1.19(6 \mathrm{H}, \mathrm{d}, J=6.7 \mathrm{~Hz}), 1.36$ $1.47(2 \mathrm{H}, \mathrm{m}), 1.71-1.82(2 \mathrm{H}, \mathrm{m}), 1.93-2.07(2 \mathrm{H}, \mathrm{m}), 4.11(2 \mathrm{H}, \mathrm{dd}, J=6.4$ $\mathrm{Hz}, J=8.9 \mathrm{HZ}), 4.18(2 \mathrm{H}, \mathrm{dd}, J=5.8 \mathrm{~Hz}, J=8.9 \mathrm{~Hz}), 7.38(2 \mathrm{H}, \mathrm{d}, J=5.5$ $\mathrm{Hz}), 7.52(2 \mathrm{H}, \mathrm{d}, J=5.5 \mathrm{~Hz}) \cdot{ }^{13} \mathrm{C}-\mathrm{NMR}\left(\mathrm{CDCl}_{3}\right), \delta(\mathrm{ppm}): 11.50,16.68$, 26.16, 35.96, 78.63, 120.32, 125.99, 130.04, 131.54, 144.69 .

\section{2,6-Dibromo-4,8-bis((S)-2-methylbutoxy)benzo[1,2-b:4,5-}

b']dithiophene (8). 4,8-Bis((S)-2-methylbutoxy)benzo[1,2-b:4,5b]dithiophene (6) $(0.99 \mathrm{~g}, 2.73 \mathrm{mmol})$ and dry THF $(190 \mathrm{~mL})$ were mixed together, then $1.6 \mathrm{M}$ in hexane $n$-BuLi $(4.0 \mathrm{~mL}, 6.4 \mathrm{mmol})$ was added dropwise to the solution at $-78^{\circ} \mathrm{C}$. The mixture was left under stirring for $2 \mathrm{~h}$ at $-78^{\circ} \mathrm{C}$, then carbon tetrabromide $(2.35 \mathrm{~g}, 7.09 \mathrm{mmol})$ was added. The mixture was left under stirring for $30 \mathrm{~min}$ at $-78{ }^{\circ} \mathrm{C}$ and $1 \mathrm{~h}$ at room temperature, then it was hydrolyzed with water $(200 \mathrm{~mL})$ and extracted with $\mathrm{CH}_{2} \mathrm{Cl}_{2}$. The combined organic phases were washed with brine, dried over anhydrous $\mathrm{Na}_{2} \mathrm{SO}_{4}$ and the solvent was removed under vacuum. The crude product was purified through column chromatography $\left(\mathrm{SiO}_{2}, n\right.$-hexane/ $\left.\mathrm{CH}_{2} \mathrm{Cl}_{2} 90: 10\right)$ to give $8(1.17 \mathrm{~g}$, yield $82 \%)$ as orange oil. ${ }^{1} \mathrm{H}-\mathrm{NMR}\left(\mathrm{CDCl}_{3}\right), \delta(\mathrm{ppm}): 1.01(6 \mathrm{H}, \mathrm{t}, J=7.4 \mathrm{~Hz}), 1.13(6 \mathrm{H}, \mathrm{d}, J=6.7$ $\mathrm{Hz}), 1.30-1.41(2 \mathrm{H}, \mathrm{m}), 1.63-1.73(2 \mathrm{H}, \mathrm{m}), 1.87-1.98(2 \mathrm{H}, \mathrm{m}), 3.98(2 \mathrm{H}$, dd, $J=6.4 \mathrm{~Hz}, J=8.8 \mathrm{~Hz}), 4.05(2 \mathrm{H}, \mathrm{dd}, J=5.8 \mathrm{~Hz}, J=8.8 \mathrm{~Hz}), 7.41$ $(2 \mathrm{H}, \mathrm{s}) .{ }^{13} \mathrm{C}-\mathrm{NMR}\left(\mathrm{CDCl}_{3}\right), \delta(\mathrm{ppm}): 11.41,16.53,26.02,35.84,78.78$, $114.92,123.05,130.72,130.94,142.64$

\section{2,6-Di([2,2'-bithiophen]-5-yl)-4,8-bis((S)-2-methylbutoxy)benzo[1,2-}

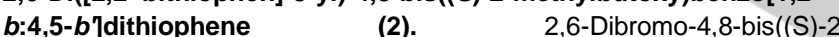
methylbutoxy)benzo[1,2-b:4,5-b']dithiophene (8) (500 mg, $0.96 \mathrm{mmol}$ ) $2 \mathrm{M} \mathrm{K}_{2} \mathrm{CO}_{3}(4.5 \mathrm{~mL})$ and 1,4-dioxane $(30 \mathrm{~mL})$ were mixed together. The solution was degassed by bubbling argon for 30 minutes, then $2,2^{\prime}$ bithiophene-5-boronic acid pinacol ester (10) (1.68 mg, $5.75 \mathrm{mmol}$ ) and $\mathrm{Pd}\left(\mathrm{PPh}_{3}\right)_{4}$ (58 $\left.\mathrm{mg}, 0.05 \mathrm{mmol}\right)$ were added. The resulting mixture was refluxed under stirring for $96 \mathrm{~h}$, then it was cooled to room temperature, hydrolyzed with saturated ammonium chloride solution $(30 \mathrm{~mL})$ and extracted with $\mathrm{CH}_{2} \mathrm{Cl}_{2}(3 \times 40 \mathrm{~mL})$. The combined organic phases were washed with brine, dried over anhydrous $\mathrm{Na}_{2} \mathrm{SO}_{4}$ and the solvent was removed under vacuum. The crude product was purified through column chromatography $\left(\mathrm{SiO}_{2}\right.$, petroleum ether $\left./ \mathrm{CH}_{2} \mathrm{Cl}_{2} 90: 10 \rightarrow 70: 30\right)$ to give 2 (199 mg, yield 30\%) as an orange solid. ${ }^{1} \mathrm{H}-\mathrm{NMR}\left(\mathrm{CDCl}_{3}\right), \delta(\mathrm{ppm}): 1.05$ $(6 \mathrm{H}, \mathrm{t}, J=7.4 \mathrm{~Hz}), 1.19(6 \mathrm{H}, \mathrm{d}, J=6.7 \mathrm{~Hz}), 1.36-1.46(2 \mathrm{H}, \mathrm{m}), 1.71-1.81$ $(2 \mathrm{H}, \mathrm{m}), 1.97-2.05(2 \mathrm{H}, \mathrm{m}), 4.06-4.10(2 \mathrm{H}, \mathrm{m}), 4.14-4.18(2 \mathrm{H}, \mathrm{m}), 7.05$ $(2 \mathrm{H}, \mathrm{dd}, J=3.6 \mathrm{~Hz}, 5.0 \mathrm{~Hz}), 7.14(2 \mathrm{H}, \mathrm{d}, J=3.8 \mathrm{~Hz}), 7.23-7.25(6 \mathrm{H}, \mathrm{m})$, $7.48(2 \mathrm{H}, \mathrm{s}) .{ }^{13} \mathrm{C}-\mathrm{NMR}\left(\mathrm{CDCl}_{3}\right), \delta(\mathrm{ppm}): 11.46,16.64,26.12,35.93$, $78.69,115.99,124.05,124.43,124.85,125.99,127.97,129.23,132.39$, $136.08,136.31,136.93,137.60,144.07$. LC-MS APCI $(+)[\mathrm{M}+\mathrm{H}]^{+}: 692.1$.

4,8-Bis(((S)-3,7-dimethyloctyl)oxy)benzo[1,2-b:4,5- $b$ ]dithiophene (7). Benzo[1,2-b:4,5-b]dithiophene-4,8-diol (5) (1.03 g, $4.63 \mathrm{mmol}$ ), (S)-1bromo-3,7-dimethyloctane $(2.56 \mathrm{~g}, 11.6 \mathrm{mmol}), \mathrm{K}_{2} \mathrm{CO}_{3}(6.40 \mathrm{~g}, 46.3$ mmol), 18-crown-6 (12 mg, $0.045 \mathrm{mmol})$ and $\mathrm{CH}_{3} \mathrm{CN}(100 \mathrm{~mL})$ were mixed together. The mixture was refluxed under stirring for $30 \mathrm{~h}$, then it was cooled to room temperature, filtered and the solvent was removed under vacuum. The residue was dissolved in $\mathrm{CH}_{2} \mathrm{Cl}_{2}(50 \mathrm{~mL})$ and washed with $\mathrm{H}_{2} \mathrm{O}(3 \times 50 \mathrm{~mL})$, then the organic phase was dried over anhydrous $\mathrm{Na}_{2} \mathrm{SO}_{4}$ and the solvent was removed under vacuum. The crude product was purified through column chromatography $\left(\mathrm{SiO}_{2}, n\right.$ hexane/ $\left.\mathrm{CH}_{2} \mathrm{Cl}_{2} 50: 50\right)$ to give 7 (2.17 g, yield 93\%) as a colourless oil. ${ }^{1} \mathrm{H}-\mathrm{NMR}\left(\mathrm{CDCl}_{3}\right), \delta(\mathrm{ppm}): 0.91(12 \mathrm{H}, \mathrm{d}, J=6.4 \mathrm{~Hz}), 1.01(6 \mathrm{H}, \mathrm{d}, J=6.8$ $\mathrm{Hz}), 1.16-1.25(6 \mathrm{H}, \mathrm{m}), 1.29-1.45(6 \mathrm{H}, \mathrm{m}), 1.52-1.62(2 \mathrm{H}, \mathrm{m}), 1.66-1.75$ $(2 \mathrm{H}, \mathrm{m}), 1.78-1.90(2 \mathrm{H}, \mathrm{m}), 1.93-2.01(2 \mathrm{H}, \mathrm{m}), 4.29-4.39(4 \mathrm{H}, \mathrm{m}), 7.36$ $(2 \mathrm{H}, \mathrm{d}, J=5.6 \mathrm{~Hz}), 7.49(2 \mathrm{H}, \mathrm{d}, J=5.6 \mathrm{~Hz}) \cdot{ }^{13} \mathrm{C}-\mathrm{NMR}\left(\mathrm{CDCl}_{3}\right), \delta(\mathrm{ppm})$ $19.70,22.60,22.70,24.68,27.94,29.74,37.32,37.60,39.25,72.15$, $120.28,125.88,130.04,131.58,144.54$.

2,6-Dibromo-4,8-bis(((S)-3,7-dimethyloctyl)oxy)benzo[1,2-b:4,5-

b]dithiophene (9). 4,8-Bis(((S)-3,7-dimethyloctyl)oxy)benzo[1,2-b:4,5b'dithiophene (7) $(0.51 \mathrm{~g}, 1.01 \mathrm{mmol})$ and dry THF $(70 \mathrm{~mL})$ were mixed together, then $1.6 \mathrm{M}$ in hexane $n$-BuLi $(1.5 \mathrm{~mL}, 2.4 \mathrm{mmol})$ was added dropwise to the solution at $-78{ }^{\circ} \mathrm{C}$. The mixture was left under stirring for $2 \mathrm{~h}$ at $-78^{\circ} \mathrm{C}$, then carbon tetrabromide $(0.87 \mathrm{~g}, 2.62 \mathrm{mmol})$ was added The mixture was left under stirring for $30 \mathrm{~min}$ at $-78^{\circ} \mathrm{C}$ and $1 \mathrm{~h}$ at room temperature, then it was hydrolyzed with water $(70 \mathrm{~mL})$ and extracted with $\mathrm{CH}_{2} \mathrm{Cl}_{2}$. The combined organic phases were washed with brine, dried over anhydrous $\mathrm{Na}_{2} \mathrm{SO}_{4}$ and the solvent was removed under vacuum. The crude product was purified through column chromatography $\left(\mathrm{SiO}_{2}\right.$, $n$-hexane $\left./ \mathrm{CH}_{2} \mathrm{Cl}_{2} 90: 10\right)$ to give $9(0.52 \mathrm{~g}$, yield $77 \%)$ as a yellowish oil. ${ }^{1} \mathrm{H}-\mathrm{NMR}\left(\mathrm{CDCl}_{3}\right), \delta(\mathrm{ppm}): 0.87(12 \mathrm{H}, \mathrm{d}, J=6.4 \mathrm{~Hz}), 0.96$ $(6 \mathrm{H}, \mathrm{d}, J=6.4 \mathrm{~Hz}), 1.11-1.20(6 \mathrm{H}, \mathrm{m}), 1.22-1.39(6 \mathrm{H}, \mathrm{m}), 1.49-1.59(2 \mathrm{H}$ $\mathrm{m}), 1.61-1.67(2 \mathrm{H}, \mathrm{m}), 1.69-1.79(2 \mathrm{H}, \mathrm{m}), 1.83-1.91(2 \mathrm{H}, \mathrm{m}), 4.17-4.26$ $(4 \mathrm{H}, \mathrm{m}), 7.40(2 \mathrm{H}, \mathrm{s}) .{ }^{13} \mathrm{C}-\mathrm{NMR}\left(\mathrm{CDCl}_{3}\right), \delta$ (ppm): 19.71, 22.61, 22.71, 24.70, 27.97, 29.72, 37.25, 37.50, 39.24, 72.45, 114.96, 123.14, 130.89, $131.07,142.57$.

4,8-Bis(((S)-3,7-dimethyloctyl)oxy)-2,6-di(thiophen-2-yl)benzo[1,2$\begin{array}{lll}b: 4,5-b] d i t h i o p h e n e & \text { (3). } & 2,6 \text {-Dibromo-4,8-bis }(((S)-3,7\end{array}$ dimethyloctyl)oxy)benzo[1,2- $b: 4,5-b$ ]dithiophene (9) (500 mg, $0.76 \mathrm{mmol}$ ), $2 \mathrm{M} \mathrm{K}_{2} \mathrm{CO}_{3}(3.5 \mathrm{~mL})$ and 1,4-dioxane $(25 \mathrm{~mL})$ were mixed together. The solution was degassed by bubbling argon for 30 minutes, then thiophene2-boronic acid pinacol ester (11) (958 mg, $4.56 \mathrm{mmol})$ and $\mathrm{Pd}\left(\mathrm{PPh}_{3}\right)_{4}(47$ $\mathrm{mg}, 0.04 \mathrm{mmol}$ ) were added. The resulting mixture was refluxed under stirring for $96 \mathrm{~h}$, then it was cooled to room temperature, hydrolyzed with saturated ammonium chloride solution $(25 \mathrm{~mL})$ and extracted with $\mathrm{CH}_{2} \mathrm{Cl}_{2}$ $(3 \times 30 \mathrm{~mL})$. The combined organic phases were washed with brine, dried over anhydrous $\mathrm{Na}_{2} \mathrm{SO}_{4}$ and the solvent was removed under vacuum. The crude product was purified through column chromatography $\left(\mathrm{SiO}_{2}\right.$, petroleum ether/ $\left.\mathrm{CH}_{2} \mathrm{Cl}_{2} 90: 10 \rightarrow 70: 30\right)$ to give $3(304 \mathrm{mg}$, yield $60 \%)$ as a yellow solid. ${ }^{1} \mathrm{H}-\mathrm{NMR}\left(\mathrm{CDCl}_{3}\right), \delta(\mathrm{ppm}): 0.88(12 \mathrm{H}, \mathrm{d}, J=6.6 \mathrm{~Hz}), 1.01$ $(6 \mathrm{H}, \mathrm{d}, J=6.6 \mathrm{~Hz}), 1.14-1.30(6 \mathrm{H}, \mathrm{m}), 1.32-1.46(6 \mathrm{H}, \mathrm{m}), 1.51-1.61(2 \mathrm{H}$ m), 1.68-1.76 (2H, m), 1.79-1.88 (2H, m), 1.92-2.00 (2H, m), 4.29-4.38 $(4 \mathrm{H}, \mathrm{m}), 7.08(2 \mathrm{H}, \mathrm{dd}, J=3.6 \mathrm{~Hz}, 5.0 \mathrm{~Hz}), 7.31-7.34(4 \mathrm{H}, \mathrm{m}), 7.50(2 \mathrm{H}, \mathrm{s})$. ${ }^{13} \mathrm{C}-\mathrm{NMR}\left(\mathrm{CDCl}_{3}\right), \delta(\mathrm{ppm}): 19.77,22.64,22.73,24.79,28.02,29.81$, $37.35,37.65,39.31,72.30,116.13,125.32,125.67,128.00,129.40$, 132.46, 136.66, 137.46, 144.01. LC-MS APCI (+) $[\mathrm{M}+\mathrm{H}]^{+}:$: 668.3.

1,4-Bis(((S)-3,7-dimethyloctyl)oxy)benzene (13). Hydroquinone (12) (401 mg, $3.64 \mathrm{mmol}$ ), (S)-1-bromo-3,7-dimethyloctane (2.02 g, 9.13 $\mathrm{mmol}), \mathrm{K}_{2} \mathrm{CO}_{3}(5.03 \mathrm{~g}, 36.4 \mathrm{mmol})$, 18 -crown-6 (4.8 mg, $\left.0.018 \mathrm{mmol}\right)$, and $\mathrm{CH}_{3} \mathrm{CN}$ (40 mL) were mixed together. The mixture was refluxed under stirring for $96 \mathrm{~h}$, then it was cooled to room temperature and concentrated under vacuum. The residue was dissolved in $\mathrm{H}_{2} \mathrm{O}(50 \mathrm{~mL})$ and extracted with $\mathrm{CH}_{2} \mathrm{Cl}_{2}(3 \times 50 \mathrm{~mL})$, then the organic phase was washed with brine, dried over anhydrous $\mathrm{Na}_{2} \mathrm{SO}_{4}$ and the solvent was removed under vacuum. The crude product was purified through column chromatography $\left(\mathrm{SiO}_{2}, n\right.$-hexane $\left.\rightarrow \mathrm{CH}_{2} \mathrm{Cl}_{2}\right)$ to give $13(1.11 \mathrm{~g}$, yield $78 \%)$ as a colourless oil. ${ }^{1} \mathrm{H}-\mathrm{NMR}\left(\mathrm{CDCl}_{3}\right), \delta(\mathrm{ppm}): 0.88(12 \mathrm{H}, \mathrm{d}, J=6.6$ $\mathrm{Hz}), 0.94(6 \mathrm{H}, \mathrm{d}, J=6.6 \mathrm{~Hz}), 1.12-1.38(12 \mathrm{H}, \mathrm{m}), 1.49-1.61(4 \mathrm{H}, \mathrm{m})$ 1.63-1.71 (2H, m), 1.77-1.85 (2H, m), 3.90-3.99 $(4 \mathrm{H}, \mathrm{m}), 6.83(4 \mathrm{H}, \mathrm{s})$ ${ }^{13} \mathrm{C}-\mathrm{NMR}\left(\mathrm{CDCl}_{3}\right), \delta(\mathrm{ppm}): 19.82,22.75,22.85,24.81,28.12,30.00$, $36.51,37.47,39.40,67.12,115.55(2 \mathrm{C}), 153.35$.

1,4-Bis(((S)-3,7-dimethyloctyl)oxy)-2,5-diiodobenzene (14). 1,4$\mathrm{Bis}\left(((S)-3,7-\right.$ dimethyloctyl)oxy)benzene (13) (997 mg, $2.55 \mathrm{mmol}), \mathrm{KIO}_{3}$ 
(221 mg, $1.03 \mathrm{mmol}), \mathrm{I}_{2}(736 \mathrm{mg}, 2.90 \mathrm{mmol}), 10 \mathrm{wt} \% \mathrm{H}_{2} \mathrm{SO}_{4}(1.5 \mathrm{~mL})$ and $\mathrm{CH}_{3} \mathrm{COOH}(15 \mathrm{~mL})$ were mixed together. The mixture was refluxed under stirring for $24 \mathrm{~h}$, then it was cooled to room temperature, treated with 20 wt\% $\mathrm{Na}_{2} \mathrm{~S}_{2} \mathrm{O}_{4}(15 \mathrm{~mL})$ and extracted with $\mathrm{CH}_{2} \mathrm{Cl}_{2}(4 \times 30 \mathrm{~mL})$. The organic phase was washed with brine $(2 \times 100 \mathrm{~mL})$, dried over anhydrous $\mathrm{Na}_{2} \mathrm{SO}_{4}$ and the solvent was removed under vacuum. The crude product was purified through column chromatography $\left(\mathrm{SiO}_{2}, n\right.$-hexane/ $\mathrm{CH}_{2} \mathrm{Cl}_{2}$ $4: 1)$ to give $14(1.10 \mathrm{~g}$, yield $67 \%)$ as a colourless oil. ${ }^{1} \mathrm{H}-\mathrm{NMR}\left(\mathrm{CDCl}_{3}\right), \delta$ (ppm): $0.89(12 \mathrm{H}, \mathrm{d}, J=6.6 \mathrm{~Hz}), 0.96(6 \mathrm{H}, \mathrm{d}, J=6.6 \mathrm{~Hz}), 1.15-1.22(4 \mathrm{H}$, $\mathrm{m}), 1.25-1.40(8 \mathrm{H}, \mathrm{m}), 1.48-1.64(4 \mathrm{H}, \mathrm{m}), 1.72-1.80(2 \mathrm{H}, \mathrm{m}), 1.82-1.90$ $(2 \mathrm{H}, \mathrm{m}), 3.91-4.01(4 \mathrm{H}, \mathrm{m}), 7.18(2 \mathrm{H}, \mathrm{s}) \cdot{ }^{13} \mathrm{C}-\mathrm{NMR}\left(\mathrm{CDCl}_{3}\right), \delta(\mathrm{ppm})$ : $19.80,22.73,22.84,24.75,28.03,29.79,36.16,37.27,39.27,68.67$, $86.35,122.72,152.90$.

\section{5,5"-(2,5-Bis(((S)-3,7-dimethyloctyl)oxy)-1,4-phenylene)di-2,2'-}

bithiophene (4). 1,4-Bis(((S)-3,7-dimethyloctyl)oxy)-2,5-diiodobenzene (14) $(520 \mathrm{mg}, 0.81 \mathrm{mmol}), 2 \mathrm{M} \mathrm{K}_{2} \mathrm{CO}_{3}(12.5 \mathrm{~mL})$ and 1,4-dioxane $(90 \mathrm{~mL})$ were mixed together. The solution was degassed by bubbling argon for 30 minutes, then 2,2'-bithiophene-5-boronic acid pinacol ester (10) (1.20 $\mathrm{g}, 4.11 \mathrm{mmol})$ and $\mathrm{Pd}\left(\mathrm{PPh}_{3}\right)_{4}(47 \mathrm{mg}, 0.04 \mathrm{mmol})$ were added. The resulting mixture was refluxed under stirring for $48 \mathrm{~h}$, then it was cooled to room temperature, hydrolyzed with a saturated ammonium chloride solution $(70 \mathrm{~mL})$ and extracted with $\mathrm{CH}_{2} \mathrm{Cl}_{2}(4 \times 50 \mathrm{~mL})$. The combined organic phases were washed with brine, dried over anhydrous $\mathrm{Na}_{2} \mathrm{SO}_{4}$ and the solvent was removed under vacuum. The crude product was purified through column chromatography $\left(\mathrm{SiO}_{2}, n\right.$-hexane $\left./ \mathrm{CH}_{2} \mathrm{Cl}_{2} 4: 1\right)$ to give $4(466 \mathrm{mg}$, yield $80 \%)$ as a yellow solid. ${ }^{1} \mathrm{H}-\mathrm{NMR}\left(\mathrm{CDCl}_{3}\right), \delta(\mathrm{ppm})$ : $0.88(12 \mathrm{H}, \mathrm{d}, J=6.6 \mathrm{~Hz}), 1.00(6 \mathrm{H}, \mathrm{d}, J=6.6 \mathrm{~Hz}), 1.14-1.45(12 \mathrm{H}, \mathrm{m})$, 1.48-1.60 (2H, m), 1.68-1.76 (2H, m), 1.79-1.87 (2H, m), 1.98-2.06 $(2 \mathrm{H}$, m), 4.13-4.21 (4H, m), $7.04(2 \mathrm{H}, \mathrm{dd}, J=4.9,3.8 \mathrm{~Hz}), 7.18(2 \mathrm{H}, \mathrm{d}, J=3.8$ $\mathrm{Hz}), 7.22(4 \mathrm{H}, \mathrm{m}), 7.26(2 \mathrm{H}, \mathrm{s}), 7.48(2 \mathrm{H}, \mathrm{d}, J=3.8 \mathrm{~Hz}) .{ }^{13} \mathrm{C}-\mathrm{NMR}$ $\left(\mathrm{CDCl}_{3}\right), \delta(\mathrm{ppm}): 19.81,22.75,22.87,24.97,28.13,30.06,36.68,37.62$, $39.44,68.13,112.14,122.87,123.44,123.65,124.32,125.96,127.98$, 137.47, 137.93, 138.27, 149.41. LC-MS APCl $(+)[\mathrm{M}+\mathrm{H}]^{+}:$720.3.

\section{Characterization}

Thin film preparation. Drop casted samples were prepared by depositing dropwise on a quartz plate $\sim 100 \mu \mathrm{L}$ of a $1.0 \cdot 10^{-3} \mathrm{M}$ solution of the oligothiophene (1, 2 and $\mathbf{3}$ in $\mathrm{CH}_{2} \mathrm{Cl}_{2} ; \mathbf{4}$ in $\mathrm{CHCl}_{3}$ ), followed by slow evaporation in an atmosphere saturated with solvent vapours. Spin coated samples were prepared by spin coating $\sim 100 \mu \mathrm{L}$ of a $2.0 \cdot 10^{-2} \mathrm{M}$ solution of the oligothiophene $\left(\mathbf{1}, 2\right.$ and 3 in $\mathrm{CH}_{2} \mathrm{Cl}_{2} ; 4$ in $\mathrm{CHCl}_{3}$ ) on a quartz plate, using a WS-400B-6NPP-LITE (Laurell Technologies Corp., North Wales, PA, USA) spin-coater. The spinning rates are indicated in the text and figures.

Spectroscopy and Microscopy. UV-Vis absorption (Abs) spectra were recorded at room temperature using a Jasco V-650 spectrophotometer. Electronic circular dichroism (ECD) spectra were recorded at room temperature using a Jasco J-710 spectropolarimeter. In all cases, at least 5 independent thin film samples were prepared and subjected to full Abs and ECD analysis. In the first place, invariance of ECD amplitudes upon sample rotation was testified, by rotating the sample by $90^{\circ}, 180^{\circ}$ and $270^{\circ}$ around the optical axis: in no cases could we observed significant variations. For each sample, then, two ECD spectra were recorded: one with the organic film facing the light source (front) and one with the organic film facing the detector (back). Each ECD spectrum was normalized to maximum amplitude to avoid any mistake possibly associated to sample inhomogeneity. The semi-sum and semi-difference of front and back ECD spectra were calculated to obtain $C_{\text {iso }}$ and LDLB respectively, as described in Eq. 3 and 4.

Optical microscopy images of thin films were obtained at room temperature using a ZEISS SteREO Discovery.V8 microscope provided with cross-polarized filters and also equipped with a camera Canon PowerShot A640.

X-ray diffraction analysis. X-ray diffraction patterns (XRD) carried out in Bragg-Brentano geometry were obtained at $20^{\circ} \mathrm{C}$ using a Siemens D-
500 diffractometer equipped with a sensible detector (VORTEX), Soller slits $\left(2^{\circ}\right)$ and narrow slits $\left(0.3^{\circ}\right)$, and a Siemens FK 60-10 2000W tube ( $\mathrm{Cu} \mathrm{K}_{\alpha}$ radiation, $\lambda=0.154 \mathrm{~nm}$ ). The operating voltage and current were $40 \mathrm{kV}$ and $40 \mathrm{~mA}$, respectively. Data were collected from $3^{\circ}$ to $33^{\circ}(2 \theta)$ at $0.05^{\circ}$ intervals ( 9 s for each one).

\section{Conflict of interest}

The authors declare no conflict of interest.

Keywords: circular dichroism $\cdot \pi$-conjugated oligomers $\bullet$ spin coating $\bullet$ supramolecular chirality $\bullet$ thin films

[1] L. A. P. Kane-Maguire, G. G. Wallace, Chem. Soc. Rev. 2010, 39, 2545-2576.

[2] M. Verswyvel, G. Koeckelberghs, Polym. Chem. 2012, 3, 3203-3216.

[3] J. R. Brandt, F. Salerno, M. J. Fuchter, Nat. Rev. Chem. 2017, 1, 0045

[4] Y. Yang, Y. Zhang, Z. Wei, Adv. Mater. 2013, 25, 6039-6049.

[5] M. Liu, L. Zhang, T. Wang, Chem. Rev. 2015, 115, 7304-7397.

[6] J. R. Brandt, X. Wang, Y. Yang, A. J. Campbell, M. J. Fuchter, J. Am. Chem. Soc. 2016, 138, 9743-9746.

[7] D.-M. Lee, J.-W. Song, Y.-J. Lee, C.-J. Yu, J.-H. Kim, Adv. Mater. 2017, 29, 1700907.

[8] F. Zinna, M. Pasini, F. Galeotti, C. Botta, L. Di Bari, U. Giovanella, Adv. Funct. Mater. 2017, 27, 1603719.

[9] Y. Yang, R. C. da Costa, M. J. Fuchter, A. J. Campbell, Nat. Photon 2013, 7, 634-638.

[10] Y. Yang, B. Rice, X. Shi, J. R. Brandt, R. C. da Costa, G. J. Hedley, D.M. Smilgies, J. M. Frost, I. D. W. Samuel, A. Otero-de-la-Roza, E. R. Johnson, K. E. Jelfs, J. Nelson, A. J. Campbell, M. J. Fuchter, ACS Nano 2017, 11, 8329-8338.

[11] X. Shang, I. Song, H. Ohtsu, Y. H. Lee, T. Zhao, T. Kojima, J. H. Jung, M. Kawano, J. H. Oh, Adv. Mater. 2017, 29, 1605828.

[12] M. Schulz, M. Mack, O. Kolloge, A. Lützen, M. Schiek, Phys. Chem Chem. Phys. 2017, 19, 6996-7008.

[13] L. Torsi, G. M. Farinola, F. Marinelli, M. C. Tanese, O. H. Omar, L. Valli, F. Babudri, F. Palmisano, P. G. Zambonin, F. Naso, Nat. Mater. 2008, 7, 412-417.

[14] D. T. Simon, E. O. Gabrielsson, K. Tybrandt, M. Berggren, Chem. Rev. 2016, 116, 13009-13041

[15] P. C. Mondal, N. Kantor-Uriel, S. P. Mathew, F. Tassinari, C. Fontanesi, R. Naaman, Adv. Mater. 2015, 27, 1924-1927.

[16] T. L. Andrew, T. M. Swager, J. Polym. Sci., Part B: Polym. Phys. 2011, 49, 476-498.

[17] G. Pescitelli, L. Di Bari, N. Berova, Chem. Soc. Rev. 2014, 43, 52115233.

[18] Y. Shindo, Opt. Eng. 1995, 34, 3369-3384.

[19] R. Kuroda, T. Harada in Comprehensive Chiroptical Spectroscopy, Eds.: N. Berova, P. L. Polavarapu, K. Nakanishi, R. W. Woody), John Wiley \& Sons, Inc., Hoboken, New Jersey, USA, 2012, pp. 91-113.

[20] D. Di Nuzzo, C. Kulkarni, B. Zhao, E. Smolinsky, F. Tassinari, S. C. J. Meskers, R. Naaman, E. W. Meijer, R. H. Friend, ACS Nano 2017, 11, 12713-12722.

[21] J. H. Freudenthal, E. Hollis, B. Kahr, Chirality 2009, 21, E20-E27.

[22] R. Kuroda, T. Harada, Y. Shindo, Rev. Sci. Instrum. 2001, 72, $3802-$ 3810

[23] M. R. Craig, P. Jonkheijm, S. C. J. Meskers, A. P. H. J. Schenning, E. W. Meijer, Adv. Mater. 2003, 15, 1435-1438.

[24] X. Cui, S. M. Nichols, O. Arteaga, J. Freudenthal, F. Paula, A. G Shtukenberg, B. Kahr, J. Am. Chem. Soc. 2016, 138, 12211-12218.

[25] Y. Shindo, Y. Ohmi, J. Am. Chem. Soc. 1985, 107, 91-97.

[26] C. Merten, T. Kowalik, A. Hartwig, Appl. Spectrosc. 2008, 62, 901-905.

[27] G. Albano, M. Lissia, G. Pescitelli, L. A. Aronica, L. Di Bari, Mater Chem. Front. 2017, 1, 2047-2056.

[28] K. Norrman, A. Ghanbari-Siahkali, N.B. Larsen, Annu. Rep. Prog Chem., Sect. C 2005, 101, 174-201. 
[29] A. Tsuda, M. A. Alam, T. Harada, T. Yamaguchi, N. Ishii, T. Aida, Angew. Chem. Int. Ed. 2007, 46, 8198-8202.

[30] M. Wolffs, S. J. George, Ž. Tomović, S. C. J. Meskers, A. P. H. J. Schenning, E. W. Meijer, Angew. Chem. Int. Ed. 2007, 46, 8203-8205.

[31] Z. El-Hachemi, O. Arteaga, A. Canillas, J. Crusats, C. Escudero, R. Kuroda, T. Harada, M. Rosa, J. M. Ribó, Chem. Eur. J. 2008, 14, 64386443.

[32] O. Arteaga, A. Canillas, J. Crusats, Z. El-Hachemi, J. Llorens, E. Sacristan, J. M. Ribo, ChemPhysChem 2010, 11, 3511-3516.

[33] Z. El-Hachemi, O. Arteaga, A. Canillas, J. Crusats, J. Llorens, J. M. Ribo, Chirality 2011, 23, 585-592.

[34] K. Okano, O. Arteaga, J. M. Ribo, T. Yamashita, Chem. Eur. J. 2011, 17, 9288-9292.

[35] X.Tang, X. Ji, Y. Li, B. Li and Y. Yang, Chem. Asian J. 2016, 11, 852 857.

[36] J. M. Ribo, Z. El-Hachemi, O. Arteaga, A. Canillas, J. Crusats, Chem. Rec. 2017, 17, 713-724.

[37] T. Yamaguchi, T. Kimura, H. Matsuda, T. Aida, Angew. Chem. Int. Ed. 2004, 43, 6350-6355.

[38] K. Okano, T. Yamashita, Polym. J. 2011, 43, 941-943.

[39] K. Mori, T. Tashiro, B. Zhao, D. M. Suckling, A. M. El-Sayed, Tetrahedron 2010, 66, 2642-2653.

[40] R. van Hameren, A. M. van Buul, M. A. Castriciano, V. Villari, N. Micali, P. Schön, S. Speller, L. Monsù Scolaro, A. E. Rowan, J. A. A. W Elemans, R. J. M. Nolte, Nano Lett. 2008, 8, 253-259.

[41] F. Zinna, C. Resta, M. Górecki, G. Pescitelli, L. Di Bari, T. Jávorfi, R. Hussain, G. Siligardi, Macromolecules 2017, 50, 2054-2060.

[42] K. Claborn, E. Puklin-Faucher, M. Kurimoto, W. Kaminsky, B. Kahr, J. Am. Chem. Soc. 2003, 125, 14825-14831. 
Table of Contents

\section{FULL PAPER}

Depending on the deposition technique, thin films of chiral oligothiophenes exhibit very large chiroptical signals, which are partly due to true $C D$ an partly to linear dichroism/linear birefringence (LDLB) interference. The LDLB spectra have the outstanding property of providing inverted signals upon sample flipping: a chiroptical heads and tails.

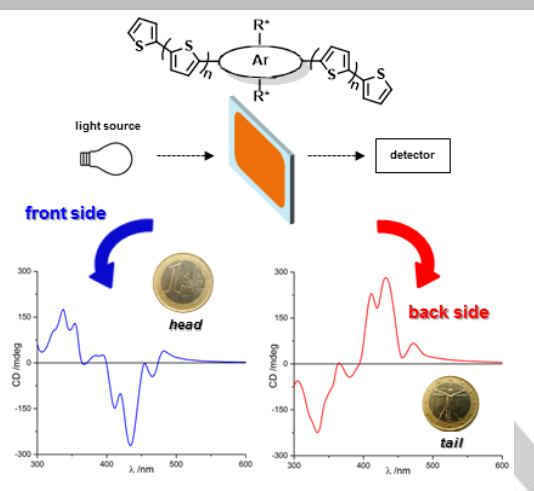

\section{Supramolecular Chirality}

Gianluigi Albano, Francesco Salerno, Lorenzo Portus, William Porzio, Laura Antonella Aronica, Lorenzo Di Bari *

Page No. - Page No.

Outstanding Chiroptical Features of Thin Films of Chiral Oligothiophenes 